\title{
RECEINED
}

JUA 21 ing

OAK RIDGE

OSTI

NATIONAL.

LABORATORY

coexweso mantis/7

\section{Testing and Transition: The Final Days of System Development}

L. F. Truett

J. P. Rollow 
This report has betn Ieproduced ofiretly from the best available copy.

Available to DOE and DOE contraclors from the Office of Scientific and Technical Information, P. O. Box 62, Oak Ridge, TN 37831; prices available from (423) 576-8401, FTS 626-8401.

Available to the publite trom the National Technical Information Service, U.S. Department of Comtmerce, 5285 Port Royal Road, Springlield, VA 22161.

This repart was prepared as an account of work sponsored by an agency of the United States Government. Neither the United States Govermment nor any agency thereof, nor any of their employees, makes any warranty, express or implied, or assumes any legal liability or responsibility for the accuracy, completeness, or usefulness of any information, apparalus, product, or process disclosed, or represents that Its use would pot tuffinge privately awned rights. Reference herein to any specific conumercial praduct, practess, or service by trade name, trademark, manufacturer, or olherwise, does not necessarity constitute or imply ils endorsement, reconimendation, or favoring by the United States Government or any agency thereof. The views and opinions of authors expressed herein do not necessarily state or reflect those of the United States Govemment of any agency thereof. 
Emergy Division

TESTING AND TRANSITION: THE FINAL DAYS OF SYSTEM DEVELORMENT

L. F. Truett J. P. Rollow

May 1996

Prepared for the

Product Management Office

Office of the Deputy Chief of Staff for Fnformation Management MILITARY TRAFFIC MANAGEMENT COMMAND

Falls Church, Virginia 22041-5050

under

Interagency Agreement DOE No. 1405-1351-A1

Prepared by

Oak Ridge National Laboratory

Oak Ridge, Tennessee 37831

manged by

LOCKHEED MARTIN ENERGY RESEARCH CORPORATION

for the

U.S. DEPARTMENT OF ENERGY

under contract No. DE-ACOS-960R22464 



\section{CONIENTS}

ABSTRACT $\ldots \ldots \ldots \ldots \ldots \ldots \ldots \ldots \ldots \ldots \ldots \ldots \ldots \ldots \ldots \ldots \ldots \ldots \ldots \ldots$

1. INTRODUCTION $\ldots \ldots \ldots \ldots \ldots \ldots \ldots \ldots \ldots \ldots \ldots \ldots \ldots \ldots \ldots \ldots \ldots \ldots 1$

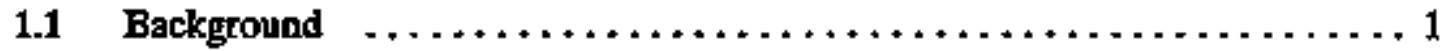

1.2 Overview of This Task $\ldots \ldots \ldots \ldots \ldots \ldots \ldots \ldots \ldots \ldots \ldots \ldots \ldots$

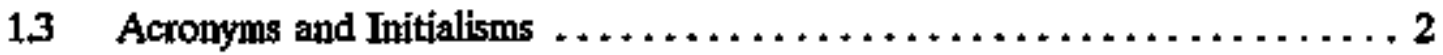

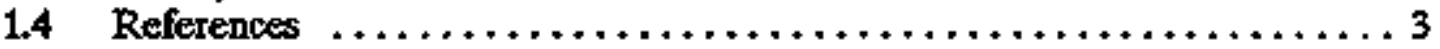

2. TESTING $\ldots \ldots \ldots \ldots \ldots \ldots \ldots \ldots \ldots \ldots \ldots \ldots \ldots \ldots \ldots \ldots \ldots \ldots \ldots \ldots \ldots$

2.1 Schedules for Testing $\ldots \ldots \ldots \ldots \ldots \ldots \ldots \ldots \ldots \ldots \ldots \ldots \ldots \ldots \ldots 5$

2.2 Functional Testing and Test Conditional Reports (TCRs) $\ldots \ldots \ldots \ldots \ldots 6$

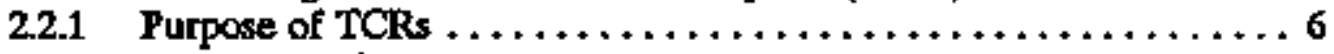

2.2 .2 Format of TCRs $\ldots \ldots \ldots \ldots \ldots \ldots \ldots \ldots \ldots \ldots \ldots \ldots \ldots$

$2.2 .3 T$ TCR Usage $\ldots \ldots \ldots \ldots \ldots \ldots \ldots \ldots \ldots \ldots \ldots \ldots \ldots \ldots \ldots$

2.2 .4 Technical (MAISRC) TCRs $\ldots \ldots \ldots \ldots \ldots \ldots \ldots \ldots \ldots \ldots \ldots \ldots$

23 Data for Testing Functionat TCRs $\ldots \ldots \ldots \ldots \ldots \ldots \ldots \ldots \ldots \ldots \ldots \ldots$

2.4 Test Order $\ldots \ldots \ldots \ldots \ldots \ldots \ldots \ldots \ldots \ldots \ldots \ldots \ldots \ldots \ldots \ldots \ldots \ldots$ 15

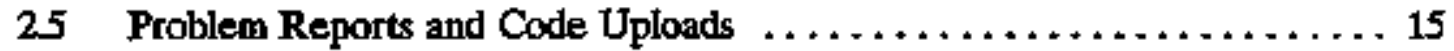

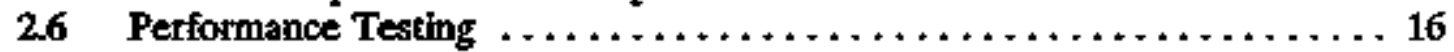

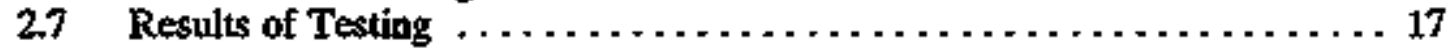

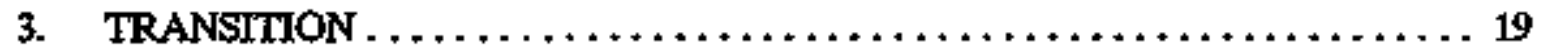

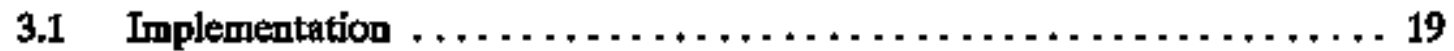

3.2 Transition to a Maintenance Contractor . . . . . . . . . . . . . . 19

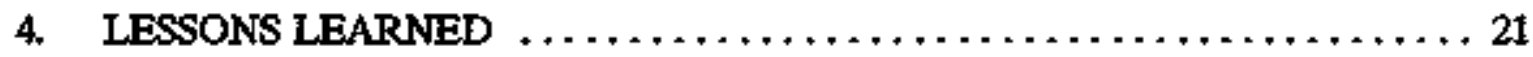

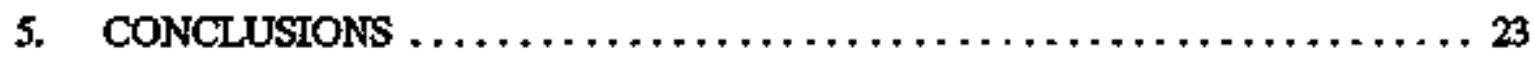

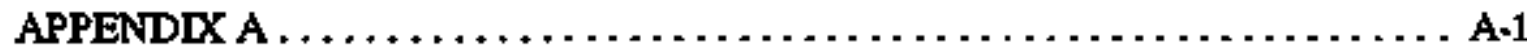

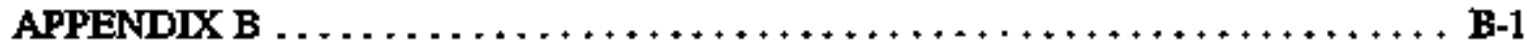

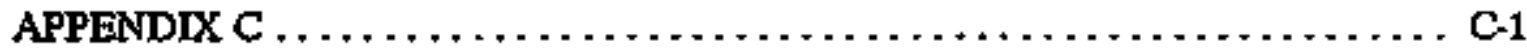

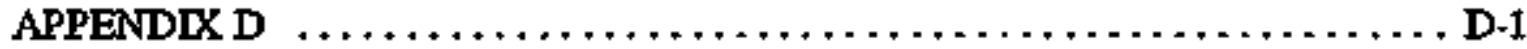

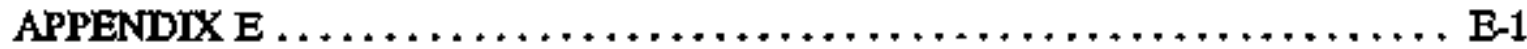

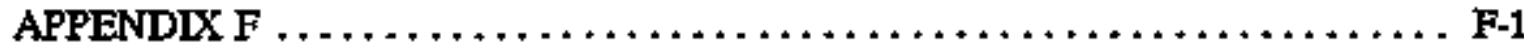

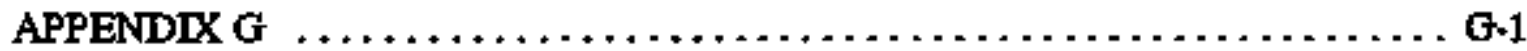




\section{LIST OF FIGURES}

2.1 Front page of $T C R$ format used for testing $\ldots \ldots \ldots \ldots \ldots \ldots \ldots \ldots \ldots$

2.2 Reverse side of a $\mathbf{T C R} \ldots \ldots \ldots \ldots \ldots \ldots \ldots \ldots \ldots \ldots \ldots \ldots \ldots \ldots \ldots$

2.3 Sample of the first page of an actual TCR $\ldots \ldots \ldots \ldots \ldots \ldots \ldots \ldots \ldots$

\section{LST OF TABLES}

2.1 Formal testing schedule of the WPS Regionai ICDB 6 


\begin{abstract}
ABSIRACT
As part of existing tasking, the Military Traffic Mandgement Command (MTMC) requested that Oak Ridge National Laboratory (ORNL) assist with writing test scenarios for the formal testing of the Worldwide Port System (WPS) Regional Integrated Cargo Database (ICDB). In collaboration with MTMC, ORNL wrote almost 600 Test Conditional Reports (TCRs), which were used to test specific functional processes. In addition, ORNL prepared the overall test order, managed tracking of problem reports and coice uploads, and interacted with the testess throughout the entire testing period.

Bexause ORNL provided analysis and design for ICDB aud because ORNL was intinately involved in development, it was unusual to be so deepiy involved in system testing. This document reports on the testing process and on lessons learned.

ORNL also assisted MTMC during the initial implementation petiod and during transition frow a developmental to a production system. A maintenance contractor was bired for ICDB, and ORNL assisted this contractor in preparing for system maintenance responsibilities. This document reports on this transition period also.
\end{abstract}





\section{INTRODUCTION}

\subsection{BACKGROUND}

The Worldwide Port System (WPS) Regional Integrated Cargo Database (ICDB) was designed and developed by personnel from the Military Traffic Management Command (MTMC) and persounel from Oak Ridge National Laboratory (ORNL). ICDB provides data integration and worldwide tracking capability for cargo that passes throngh common-user ocean cargo ports. ICDB is a data repository for the WPS terminal-level system, is a primary source for queries and cargo traffie reports, receives data from and provides data to other MTMC and non-MTMC systems, provides capabilities for processing booking records and cargo shipment documentation, distributes manifests, and provides regional managers with capabilities for managing cargo and monitoring cargo information. ICDB provides an integrated database for efficient and reljable data management, data manipulation, and data distribution.

Conforming to the requirements of Autostrad-2000 (A-2000), which implies an open systems design, ICDB resides on a Unix platform with Oracle 7 as the relational database management system (RDBMS). The basic ICDB architectural design consists of a single worldwide central database server and multiple regional processing hubs. In the Continental United States (CONUS), there is a hub on each coast. ORNL was involved only in CONUS development. Port sites are connected to either a west or east coast hub. The primary source of data to ICDB is from the WPS terminal-level system, boated at the ports.

System development started in early 1993. The WPS terminal-level system for CONUS functionality was developed by WPS personnel located at MTMC Western Area, Oakland, California. ICDB developers included ORNL personnel and MTMC personnel located at MTMC Information Management, Eastern Area (IME). Formal testiag began in eariy 1995. Testing was completed, the system was accepted, and implementation began on the West Coast in August of 1995.

\section{OVERVIEW OF THIS TASK}

The WPS terminal-level system was implemented Outside the United States (OCONUS) prior to development of the CONUS WPS and ICDB. The OCONUS regional database for the 
WPS terminal-level system is a data repository with ad hoc query capabilities, but the CONUS regional database (ICDB) is a sophisticated database with extensive state-of-the-art capabilities. Although the OCONUS WPS had successfully completed Major Army Information System Review Coumcil (MAISRC) testing, the ICDB was significantly different; thus, it was required to undergo MAISRC neview as a new system.

Tasking was assigned to ORNL to assist with writing test sceparios for the formal MAISRC testing of the functional requirements of ICDB. ORNL was provided a format for Test Conditional Reports (TCRs) and was assigned responsibility for writing TCRs to test the functionality of the system. Additional TCRs were written to test other portions (e.g., background processes, performance) of ICDB. Some of these TCRs were prepared by ORNL and some by the MAISRC test representative.

ORNL was asked to assist the maintenance contractor during the transition from a development mode to a working system. Betause of the demands of development and testing, there was very little time to meet with and train the maintenance contractor. ORNL prepared a booklet of training materials and hosted two training sessions toward the end of ORNL's iavolvement in the project

\subsection{ACRONYMS AND INITIAIUSMS}

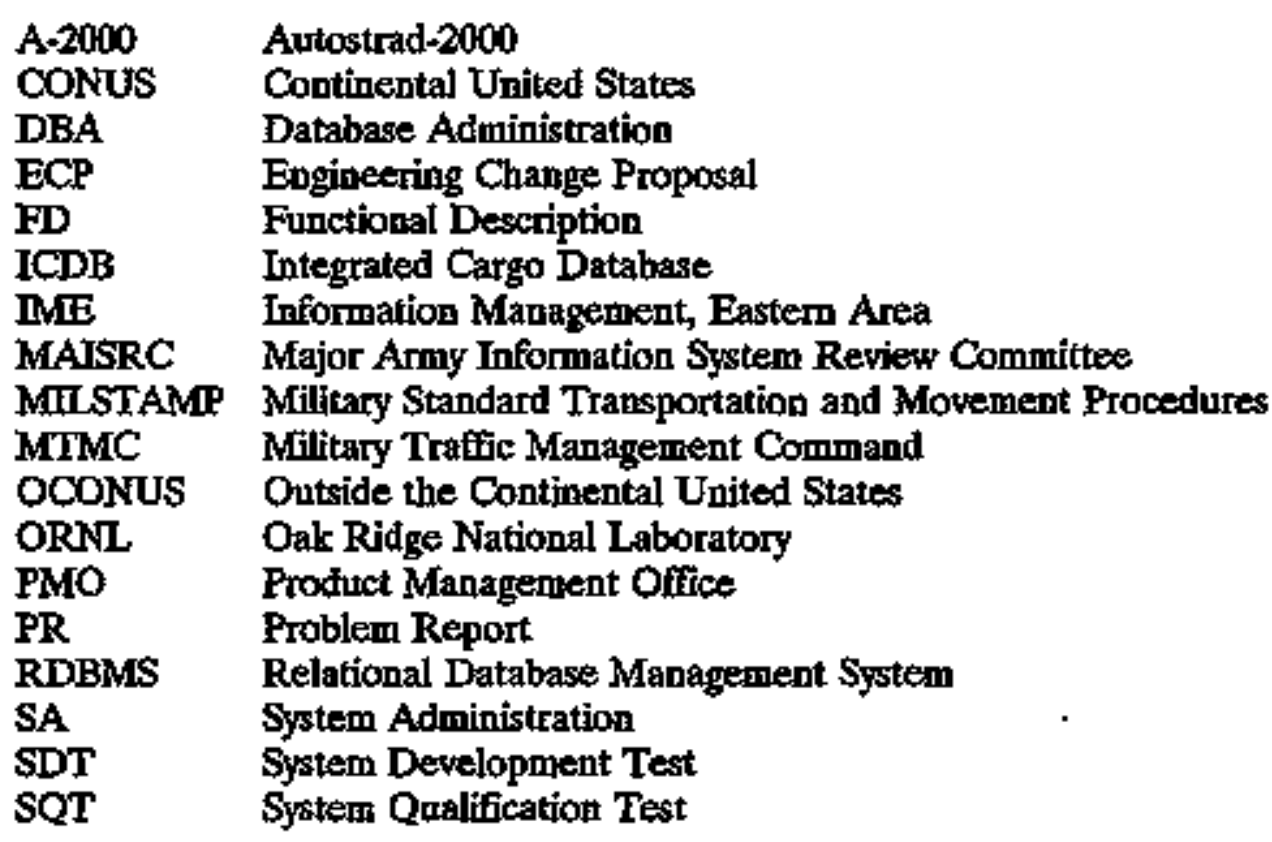


TCN Transportation Control Number

TCR Test Conditional Report

WPS Workdwide Port System

\subsection{REAERENCES}

Oak Ridge National Laboratory- Database Specifications for the Worldwide Port Sustem (WPS) Regional Integrated Database (ICDB). UNCLASSIFIED. ORNL/TM-12725. March 1994.

Oak Ridge National Laboratory. Architectural Analysis for the Worldwide Port System (WPS) Regional Integrated Database (ICDB). UNCLASSIFIED. ORNL/TM-12357. April 1993.

Oak Ridge National Laboratory. Functional Description for the Worldwide Port System (WPS) Regional Integrated Database (ICDB). UNCLASSIFIED. DRAFT November 1992, revised January 1993, revised November 1993; ORNL/TM-13118. November 1995.

Oak Ridge National Laboratory. Standards and Conventions for the Worldwide Port System (WPS) Regiongl Integrated Cargo Database (ICDB). UNCLASSIFIED. ORNL/TM12799. February 1995.

Oak Ridge National Laboratory. System/Subsystem Specifications for the Worldwide Port System (WPS) Regional Integcated Cargo Database (ICDB). UNCLASSIFIED. FINAL DRAFT, September 1995; ORNL/TM-13119. November 1995. 


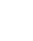




\section{TESIING}

Testing occurred throughout the development petiod at individual development sites for specific applications and for integration of the code among WPS, IME, and ORNL developers. These tests were limited by the state of development and the architectural platform at any particular point in time. In December 1993, a platform of production hardware was made available. In 1994, ORNL designed and developed a multi-threaded approach to database and code maintenance on the production architecture (the central server and two hubs). The three database threads, which are defined below, provided excellent opportunities for testing ICDB functionality and for managing changes to the developmental code.

- DEMO. This database was used by the MTMC ICDB Product Management Office (PMO) to demonstrate ICDB menus and screens to end users.

- TEST. This database was for testing of new code.

- PROD. After code and/or schema changes were tested (in the TEST thread), they were uploaded to PROD.

In late October until early December of 1994, PMO conducted intensive testing of the system as far as it could be tested at that time. This testing was limited by the fact that cone to load data from ICDB into WPS had not been developed at that point in time, and, therefore, this major component could not be tested. During PMO testing, PMO wrote problem reports, and the responsibility for correction was assigned to either IME or ORNL. Most of the problems, though not all, were corrected prior to the end of 1994.

The primary purpose of this document is to report on the more official testing which occurred toward the end of the project (throughout the first nine months of 1995). These tests were monitored by MAISRC testers. The required tests were established by MAISRC and included the System Development Test (SDT) and System Qualification Test (SQT).

\subsection{SCHEDULES FOR TESTWNG}

Tests included semiformal (pre-SDT), formal (SDT-Y and SDT-I), and very formal (SQT-I and SQT-II) formats. Table 2.1 gives the scheduje for these tests. 
Table 2.1. Fonmal testing schedule of the WPS Regional ICDB

\begin{tabular}{|l|l|l|}
\hline \multicolumn{1}{|c|}{ Test } & \multicolumn{1}{c|}{ Dates } & \multicolumn{1}{c|}{ Place } \\
\hline pre-SDT & Jan 9-Jan 20, 1995 & Oakland, Callfornia \\
\hline SDT-I & Jan 30-Mar 3, 1995 & Oakland, California \\
\hline SQT-I & Apr 24-Jun 1, 1995 & Oakland, California \\
\hline SDT-I & Jal 10-Jul 21, 1995 & Falk Church, Virginia \\
\hline SQT-II & Aug 7-Aug 25, 1995 & Oakland, Catifiornia \\
\hline
\end{tabular}

When testing began with WPS, representatives of the ICDB developnent sites (ORNL, IME), PMO, and WPS met at Westem Area, along with testers who were selected from the pool of future system users. WRS personnel made all arrangements for the test sites and for testing personnel.

The testing scenarios (TCRs) and the test plan established during SDT were used by MAISRC personnel for the SQT. In addition, MAISRC personnel developed a separate set of TCRs for testing performance - both capacity levels and tining. The TCRs for evaluating performance (see also Section 22.4) were used in SQT-I, SDT-II, and SQT-II only.

\section{FUNCTIONAL TESTHG AND TEST CONDIIONAL REPORTS (TCRs)}

ORNL was a primaty developer of ICDB and expected that an independent testing organization would be employed to prepare the testing procedures. MAISRC personnel were in charge of the testing process, developed the TCR format, and established the testing procedures as discussed in the following sections. However, ORNL was assigned the responsibilities of writing individual functional TCRs and ceveloping the test order. WPS and PMO also wrote functional TCRs.

\section{Purposes of TCRs}

The purpose of the functional TCRs was to test specific requirements. Because the final test acceptance wa determined by MAISRC personnel, a very clearly defined set of tests which 
identified and tested each functional process was necessary. In addition, different testers were used in the formal tests (e.g., SDT, SQT); thus, the testers were unfamiliar with the system and had to leatn how the system worked at the same time that they were trying to test it. The TCRs were a mechanism to provide sufficient control to both train and test at the same time.

\section{Format of TCRs}

The TCR format provided a very steuctured scenario for testing. The TCRs were written using a predetermined format established by MAISRC. A diskette with the establisbed format: using a word-processing software was provided to ORNL. The format is shown in Figure 21 (the front of a TCR form) and Figure 2.2 (the reverse side of a TCR). The front side of a sample TCR, as given to a tester, is shown in Figure 2.3. The reverse side was completed in hand writing by the tester during testing and retained by MAISRC persontrel for a permanent recond of test results.

In the TCR header block (see Figure 2.1), the following conventions were followed. "TCR No." was a shorthand identifier. TCRs initiated by ORNL used a numbering scheme based on the Functional Description (FD) requirements in the WPS FD, Appendix A, combined with the numbering scheme in the ICDB FD. TCRs initiated by WPS used a numbering scheme based on the cargo status as export or import The "Date Prepared" and "Preparer's Name" were completed by the preparer. The next extry, "ECP No." which stood for Enginecring Change Proposal, was left blank during writing of the TCR. An ECP number was assigned if a routine problem was identified which did not require changes during the SQT. The ECP number allowed the problem to be tracked for future correction. The entry for "Input Medium" was always screen for the functional TCRs.

In the body of the TCR, the "Test Puppose" stated the functionality to be tested; "FD Reference" was a reference to the pages in the WPS FD, Appendix A, which provided a very brief explanation of the primary functions of ICDB; "Related Programs" listed particular preceding or following TCRs, technical TCRs (written by ORNL) to load required data, or technical TCRs (written by ORNL) to test background processes to ensure that the functionality was successful; "Condition to be Evaluated" was similar to "Test Purpase," atthough more concise. 
ADSM-25-135-E01-WPS-HPC-PT

30 June 1993

TEST CONDITION REQUIREMENT (TCR)

WORLDWIDE PORT SYSIEM (WPS)

\begin{tabular}{|l|l|l|l|l|}
\hline TCR NO: & DATE PREPARED: & PREPARER'S NAME: & ECP NO: & $\begin{array}{l}\text { INPUT } \\
\text { MEDIUM: } \\
\text { Screen }\end{array}$ \\
\hline
\end{tabular}

TEST PURPOSE:

FD RFFERENCE:

REIATED PROGRAMS;

CONDMTON TO BE EVALUUATET:

TEST PROCEDURES:

EXPECTED OUTPUT:

GENERATED TRANSACMONSREPORTS:

DATABASE CHANGES EXPECTED:

Figure 2.1. Front page of TCR format used for testing. 


\section{ADSM-25-L35-F01-WPS-HPC-PT}

30 Jone 1993

TEST CONDITION REQUIREMENT (TCR)

WORLDWIIE PORT SYSTEM (WPS)

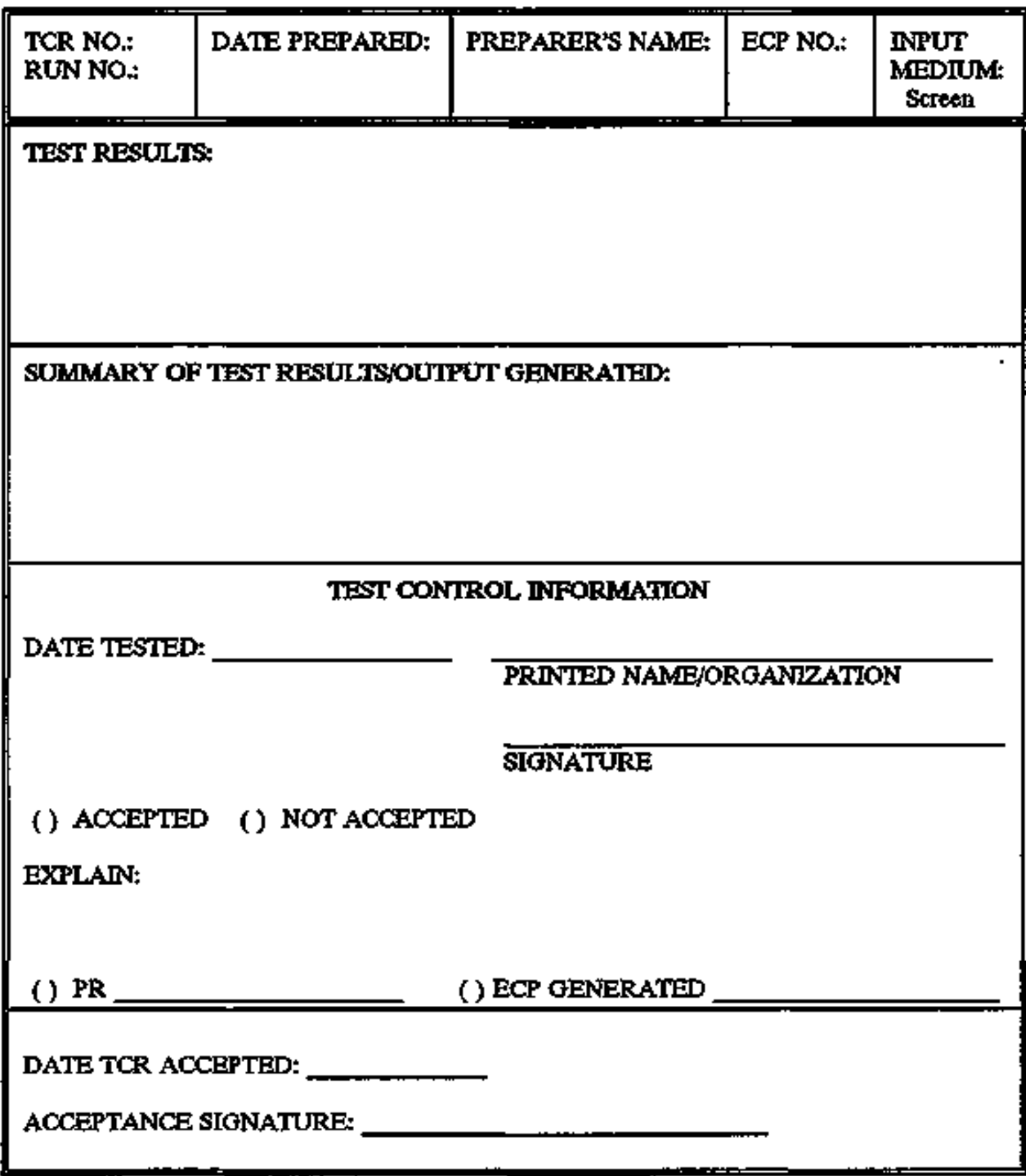

Figure 2.2. Reverse side of a TCR. 


\section{ADSM-25-L35-F01-WPS-EPC-PT \\ 30 Jane 1993 \\ TEST CONDITION REQUIREMENT (TCR) \\ WORLDWIDE PORT SYSTEM (WPS)}

\begin{tabular}{|l|l|l|l|l|}
\hline $\begin{array}{l}\text { TCR NO: } \\
\text { G4112a: }\end{array}$ & $\begin{array}{l}\text { DATE PREPARED: } \\
\text { June } 1955\end{array}$ & $\begin{array}{l}\text { PREPARERS NAME: } \\
\text { Truett }\end{array}$ & ECP NO: & $\begin{array}{l}\text { INPUT } \\
\text { MEDIUM: } \\
\text { SGreed }\end{array}$ \\
\hline \hline
\end{tabular}

TEST PURPOSE: To ensure that manifest recotds reported on a tard-wopy report of manifests faring quality valfidation routines can be corrected

FD REFEREVCE: WPS FD Aqpendix A, pq, 36-37

REIATED PROGRAMS: G4tech-112al, WPS TCR to ensure that the correated rexord is transmitted to the appropriate WPS site.

CONDIMON TO BE EVALUATED: Ertar comection

TEST PROCEDURES:

Note: Tester will be suppited with a Itst of userds and passwords for spectile roles (Attachment 1).

1. Log on as puser2

2. Select Regtonal Processes (S) press Enter.

3. Seleat Prit Reject Listing (4); press Eater.

4. Select PJibt Mapifest Reject Iisting (2); press Enter. When tie pop-ip windon appears for ideatifyng a printer, press F9 to obtain a list of avalabte printers. Use the UP/DOWN andory keys to identify the printer you desire to use; press Eater three times (to select the primter agrne, to continute, and to kturn to the application sereen).

5. Obtain the printout of rejected records. Note the grject yessan on the primtout for refected records. You will be porrecting varions records.

6. Use the UPJDOWN arrow keys to select Return to Regjonal Processes Mfeno (4), wress Enter.

7. Select Edlt Import Manliests (2); press Enter.

B. The cursor is in the Control NBR fteld. Enter the Controd NHR from the itsting printed eartier. Enter the Controt NBR that matrtes TCN = MREJ00XXXXXXXXKKK2. Press F8. Notes the reject reason on the listing invalid POD). Tab to POD and ange the POD to 3DK Press Fio to subuit the revised POD and its associated trailes data.

9. Press S-F10 to exit the screen.

10. Repeat Steps 7.9 for TCN $=$ MREJ00XXXXXXXXXZX Change POD to 3DK Press F10 to commit.

11. Repeat Steps 7-9 for TCN = MREI10BaXXXXXXXXX. Change POD to 3DK Commit

12. Repeat Steps 7-9 for TCN = MRET10XXXXXXXXIKK2 Change PK to ZR. Commile

13. Repeat Steps 7-9 for TCN $=$ MRES20 XXXXXKKK2. Change the TCN to MREJ20FINXXCXXXKK2, Comimit.

14. Repeat Steps 7.9 for TCN = MREj20BBXXXXXXXXX. Change PK to BX. Commit.

10. Exit.

EXPECTED OUTPUT: NoDe

GENERATED TRANSACTONSIREPORTS: None

DATABASE CHANGES EXPECTED: Corrected tecotd is tent to WPS

Figure 23. Sample of the first page of an actual TCR. 
In the next block, the "Test Procedures" were clearly written, step by step. Each proceduro began with a vetb, and no action (either a choice of data to be entered or a key to be pressed) was left to randon choice. Every act of the tester was very carefully orchestrated in advance.

The last section on the front page of the TCR listed the "Expected Output," "Generated Transections/Reports," and "Database Changes Expected." The tester bad the responsibility to ensure that the expected results documented in this section of the TCR matched the actual results demonstrated during the test. If data was passed to WPS, a follow-on TCR checked the conditions at the terminal.

\section{TCR Usage}

Each TCR tested a separate specific function of ICDB. A listing of all functional TCRs is provided in Appendix A. These TCRs were sorted into "test sets" which are discussed in Section 2.4, "Test Plan." All functional TCRs were written as if the user were accessing the functional menu and application screens of the ICDB user interface. This method was jdeal for guerying or for producing reports, and it was also ideal for the WPS terminal-level functionality of data entry. However, it was not adequate for testing any background processes (e.g., distributing code tables to the hubs and the WPS sites, resending data, and creating and sending data files to other organizations). These processes were initiated through screen applications and might appear to be successful to the functional user, but they actually occurred in the background and could not be checked through the user interface. To check these processes, the tester needed to be able to log into Oracle's SQL*Plus and create SQL*Plus queries to check local and remote Oracle tables. Therefore, ORNL wrote additional technical TCRs which were required for performing and/or testing the background processes. Actions required by the technical TCRs written by ORNL were performed by an ICDB or a WPS System Administrator (SA) or Database Administrator (DBA). A listing of these TCRs is provided in Appendix B.

Because certain kinds of records could enter the system either at the hubs or at WPS terminals, TCRs had to be written to test data flows from all data entry prints. Therefore, the TCRs could be either "initjating" or "follow-oin" depending on where data entered the system. In addition, records could enter the system either via on-line-bufli screens (manual data entry) or via flat files that were then processed through validation routines (batch data entry). 
For manual data entry, testers were given precise instructions on the data to be entered. For batch data, the flat files were also prepared in advance in order to maintain control. Printouts of the flat file tayout of reconds in Military Standard Transportation and Movement Procedures (MIISTAMP) 80-column format were provided to testers. (Additional information about the data used for testing is supplied in Section 2.3.)

If data entered the system at one of the ICDB hubs, the ORNL TCRs were written from a point of view which tested data initiating at the bubs. WPS wrote follow-on TCRs to test the receipt of that data at the appropriate terminal. The TCRs normally instructed the user to view a specific record on both ICDB and WPS screens and in the flat fille printout (for batchloaded reconds). The TCRs for these tests are listed in Appendix A, Test Sets 1-1 through 1-24. When the data displayed at ICDB did not equal the data displayed at WPS or when the data at either site did not agree with the flat file layout, a problen was noted. (Additional information about problem reporting is given in Section 2.5.)

If data entered the system at the WPS sites (either as a new record or as status changes), WPS personnel wrote the initiating TCRs, and the follow-on TCRs (written by ORNL and PMO) tested the receipt of that data at the central database. The primary purpose of the follow-on TCR was to ensure that data displayed on the WPS teminal-level screen could also be viewed correctly in ICDB, if regitired. (Some fields were specific to terminal-level processizing and did not appear in ICDB.) A list of these TCRs is given in Appendix A, Test Sets 2-1 through 2-10.

In addition, some ORNL TCRs tested functionality that did mot require WPS follow-on testing. And some WPS TCRs did not reguire follow-on testing at ICDB. These TCRs are also inchuded in the Test Sets listed in Appendix A

\section{Technical (MAISRC) TCRs}

A totally separate set of technieal TCRs was written and tested by the MAISRC test administrator using the same format was wsed for the functional TCRs. These technical TCRs tested the following processes: (1) communication processing and the automatic switching from network access to modem access when a normal communication line was unavailable, (2) performance times for queries based on number of users logged in, (3) performance times for transfering specified numbers of records based on the total 
number of records in the database, (4) performance times for transfering specified numbers of records from several sites almost simultaneously, (S) ability of users to log in via a 1-800 number, (6) data extracts production of and acceptance by appropriate receiving agencies, (7) security, and (8) backup and restore capabilities.

ORNL reviewed the technical TCRs prepared by MAISRC. During the technical testing, ORNL also supported the terting agency (MAISRC) and responded to issues and problems. The technical testing was very significant because it tested major components of the system (e.g, communications, performance, and automated data extraction). This report, however, emphasizes the furctional testing because ORNL did not write the TCRs for the technical tasks. The results of the performance testing are addressed in Section 2.6.

\subsection{DATA FOR TESTING FUNCTIONAL TCRs}

Obtaining a large volume of data for testing was a major problem. Although MTMC, through the Area Commands, provided certain test data sets, these did not cover all conditions. The PMO establistied a plan for constructing data sets that would ensure a sample of data within each commodity category (e.g, hazardous, personal property, ammunition). MTMC transportation managers use a Transportation Control Number (TCN) to identify cargo shipments. The PMO plan was to alter this 17 -position TCN identifier in such a way that it would provide the following information for test purposes: port indicator (for those ports being used in the test), type of cargo (i.e, containerized or breakbulk), commodity type, container number or piece count, and content number. The remaining positions in the revised TCN were usually filled with "X"s except in sperial ases (e.g, personal property shipments and unit moves). This TCN structure was provided to the testers as an attachment to the TCRs and was cross-referenced in the TCRs. The PMO also determined that a certain number of each type of record would be required. This information was also provided to the testers. The TCN structure for the test data sets and the list of TCNis in each category are provided in Appendix C.

The original intention of PMO was to obtain sufficient "teal" data for each of the appropriate categories and then change the TCNs to match the format shown in Appendix C. However, because of problems on the MME hardware and because cargo in every record category was not shipped during the time frame for obtaining records, actual data for all cargo types was not obtained. Because the TCRs were written in such a precise manner, the exact TCNis were 
needed to complete the TCRs. As time grew closer to actual testing and ORNL could not complete the TCRs, ORNL personnel constructed the test data sets from the available data

ORNL selected files of "real" data, either cargo shipment records or manifests. Because of the desire to have example data from multiple cargo "types," the raw data files were occasionality modified from the "real" data sets. For example, some cargo shipment records were used to make manifest records and some manifest records were modified as cargo shipment records. In addition, the preliminary booking data was adapted from cargo shipment records to ensure that the records would match.

These data sets were used as input to the system (to ensure that certain records with specific TCNs would be available to the testers). The flat files were also printed out, and this hardcopy of the record layouts was provided to the testers. This flat-file record layout was lengthy and is not reproduced in this document Other data sets were also formulated by ORNL as needed. A list of all of the types of data that was reproduced is given in Appendix D.

Because of the way the data was derived, sometimes the data was "inaccurate." For example, the Gat file of data for a cargo shipment might contain a field that was actually a manifest Gield (e.g, stow. location). Although the system was intelligent enough to krow during the processing of this file not to insert data into a stow location field in the database for a shipment record of cargo that had not actually been stowed, the appearance of this piece of data on the printout of the flat file was confusing to the testers. Therefore, the testers were instructed to ask the Test Coordinator for assistance if they were unsure about the data in a bield.

Sometimes the testers were confused because of system functionality with which they were unfamiliar. For example, ICDB was designed to re-compute the pieces, weight, and cube for a van based on a sum of all of the content records. Therefore, the total summed value for the pieces, weight, and cube of a van's contents on the flat file printout might not agree with the data contained in the database and displayed on the screen. The tester was invited to test the computational powers of the system by summing the pieces, weight, and cube of each content record for the vas.

The TCRs that tested the on-line build functionality of the system also had certain limitations, primarily based on the tester's data entry abilities. (For example, the tester performing data entry might type "abodefg" rather than "mnopqus" for a van number. When a tester using a 
separate TCR queried for van number "mnopqrs" using the instructions on the TCR, that van number would not exist because it bad been mistyped.) Caveats were built into user instructions for this occurrence. Testers were reminded that records built via the on-line build screens did not always conform to the instructions provided in the TCR. Therefore, if there was a discrepancy, the tester was instructed to check with the Test Coordinator.

It is important to note that the data sets described above were developed and used ONLY for the formal tests described in this document "Real" data was used throughout ICDB development for site and integration testing. It is only when using actual real-world data that real-wordd problems can be identified.

\subsection{TEST ORDER}

Prior to formal testing, PMO designed the format for a form that could be used to provide order to the testing. ORNL was assigned the respossibility to further develop this test order to ensure that all functionality would be tested. Because some of the intelligence in ICDB is to match records based on certain criteria (e.g., cargo shipment records to booking records), the data had to be loaded in a certain order to test all conditions. The sequence in which data entered the database affected how the information was incorporated into the cargo record, and a careful control of the sequencing was required to test this logic. ORNL developed a two-phase approach as the mast efficient method. This allowed testing of the WPS teminallevel data entry to proceed at the same time that data was being entered at the Hubs. This daal process of adding data at two sources concutrently was possible because different record identifiers were used. It helped to speed up the data entry part of the test. The test order (a blank copy is reproduced in Appendix E) allowed the test coordinator to maintain contzol of the propesses and to ensure that they occurred in the appropriate sequence. The test sets listed in Appendices B and A, respectively, are referenced in the second and third columns of the test order (Appendix E). Each day, primary contacts from ORNL, IME, PMO, and WPS met with the MLAISRC tester to update the test order.

\section{PROBLEM REPORTS AND CODE UPLOADS}

During SQT, when testers identified problems, they initiated a problem report (see Appendix F, Figure F.1). At the end of each day, personnel from WPS, ORNL, PMO, and MME, met 
with the MAISRC coordinator to determine if a problem report was really a problem or a misunderstanding on the tester's part. If a problem actually existed, a priority was assigned,' and the responsibility for correction was determined. Then the problem was assigned a Problem Report (PR) number and was logged in as needing correction. If the responsibility for correction fell to WPS, usually the problem report was not entered into the log because the functionality of the termital-level system was outside of the purview of testing for the WPS Regional ICDB.

A procedure was established for uploading code to fix the problems (see Appendix F, Figure F.2). After a correction had been made by the responsible developing agency, ORNL performed all uploads to ICDB, whether the problem was fixed by ORNL, by IME, or by WPS. The terminal-level system had already been approved through the formal MAISRC testing process. Therefore, if the problem was strictly a terminal-level issue, then WPS controlled code uploads to the WPS test system and the problem report was not a formal part of the testing documentation.

Once code had been revised and the fix tested on the development system, ORNL, would request a code upload. The MAISRC test coordinator would approve the upload, and the TCR which was being used for testing when the problem report had been written would be used for retesting. In some cases an eatire test set of functional TCRs would need to be retested in order to retest one TCR. Based on the resulss of retesting, the problem log would be updated.

\section{PERFORMANCE TESTING}

Performance testing was of two types: inquiry response time (including reports production) and data transfershoads with a full database ( 9 million rows). These performance requizements are given in Appendix $G$.

Prior to testing with a fully loaded database, all performances easily met required timeframes. Based on ORNL experience, performance tuning is best done with a large amount of data;

\footnotetext{
'These priorities were "Emergency" conditions, requiring 24-hour tarmaround time for corrections; "Urgent" conditions, requiring correction as quickly as possible; and "Routiale" changes, which did not require changes prior to implementation. These lathels were assigned acoording to DA Pamphlet 25-6, "Configuration Management for Automated Information Systems."
} 
therefore, ORNL had done no performance tuning with the limited data available. Because of other commitments and the prolonged functional testing schedule, MTMC was unable to obtain 9 million rows of cargo data early enough to do performance testing in advance. Therefore, no performance testing was conducted until the end of the first SQT.

Thus, because the system had never been tested with a significant amount of data, ORNL expected that performance tuning would be required, and, when a full database was loaded, performance was identified as a siguificant problem for both (1) inquiries and (2) data transfers.

The inquiries were performed from the user interface screens (see Appendix G, first, second, fourth, and sixth activities listed). When the system could not meet performance requirements for inquiries, ORNL personnel analyzed the problems and added some additional indenes. This solved the majority of the performance problems for inquiries.

When the system could tot meet performance requirements for data transfer processes (see Appendix $G$, seventh through tenth activities listed), it was a much larger problem and more difficult to solve. The transfer and conversion processes were complicated; usually a single transfer process called many different scripts and procedures.

ICDB was required to poll each WPS terminal site every five minutes and pull all changed records (up to a maximum of $\mathbf{1 0 0 0}$ records). This requirement was tested after the requirements for the user interface inquiries had been passed. The data transfer and loading processes had always been very rapid, until the database contained 9 million rows. The procedures for inserting and/or updating 1000 records into a database of this size totally failed the 5-minute requirement. Analyzing the performance problems (while still testing furpctional ECPs) and finding and implementing solutions took considerable time during the last week of SOT-I. ORNL could not analyze and tune all of the data transfer procedures. Therefote, SDT and SQT had to be repeated after one-month interruption for performance tuning.

During this month, MTMC personnel, the Oracle cosporation, ORNL, and other MTMC conttactors worked to tune database parameters, scripts, and procedures. The month was adequate to ideatify primary performance problens and determine the best solutions. Also, an upgrade to the next version of Oracle's RDBMS was required to use the Trace utility. Oracle's Trace showed exactly which statements were slowing down performance for known 
problens. ORNL was able to tewrite the data transfer procedures in order to significantly inprove performance.

During the month allotted for performance tuning and the Oracie upgrade, ORNL also rewrote scripts for performing backups and assisted MTMC in establishing guidelines for ensurigg that MTMC personnel responsible for backup and restore procedures had an established protocoi for completing these responsibilitics.

\section{RESUITS OF TFSIING}

After the first SQT, ORNL and PMO spent one month upgrading and tuning the system. Then SDT-II retested functionality and performance to ensure that everything was functioning as expected. SQT-II began shortly after SDT-II and was completed in only half the time that had been spent on SOT-I. The system was accepted and implementation began the next weekend! 


\section{TRANSITION}

There is a charged atmosphere when transitioning a development software system into production. The exercise is no longer a practice; it is no longer in testing it is being put into use. ORNL was not present at the WPS sites or the ICDB hubs or the central server when the system "went live," but ORNL personnel were available to provide assistance and/or advice when needed. This section is a brief overview of the first few weeks of implementation, during which developmental control of the software and maintenance of the sofitware passed from ORNL to MTMC and the maintenance contractor.

\subsection{IMPLEMENTATION}

Implementation of the system began on the weekend following the successful conclusion of SQT II. As real-world users began using the system, unforeseen problems related primarily to (1) data and (2) performance tuning occurred. After less than three months of actual operation, most CONUS terminals were transitioned into WPS sites, and the data feeds toffrom ICDB continued to grow in number and size. Performance tuning situations continued to show np. Although the performance problems that were identified and fixed prior to SQTII remained "iixed," as new sites were implemented and the volume of dats increased, other performance problems arose. ORNL worked with the PMO as requested to resolve these problems during the transition period.

\section{TRANSITION TO A MAINTENANCE CONTRACTOR}

The ORNL team was gradially phased out as the maintenance contractor was brought on. ORNL prepared a "training" document and hosted mainteuance contractor personnel for two visits. The training document covered the major components of the system as well as methods for trouble-shooting and performance tuning. The sections of the training document included the following:

- an overview of how why the system was designed,

- system administration/database administration functions,

- an overview of the "will to live" and communications, 
- data transfers to other organizations,

- data transfers from/to the server, bubs, and sites,

- user interface processes,

- trouble-shooting strategies, and

- performance tuning strategies.

The section on trouble shooting used a pisilosophy that was very valuable to ORNL during the analysis of problems identified during testing. The process included saving data into temporary tables at various stages during data transfer and conversion. Saving data (even temporarily) becomes a performance issue in a real-world situation, and this strategy is no Ionger used for analyzing problems.

ICDB is an extremely compiticated system, and the transition was not altogether smooth. Tekephone conferences were valuable. Also, two subcontractors who bad been with the ORNL development team for a lengthy period of time were put on contract by the maintenance contractor during the transition. This decision has proved to be very useful.

Because the schedule for testing, fixing, and retesting the code was so short, ORNL staff had very little time when they could be available to the maintenance contractor. During the spring and summer of 1995, some ORNL staff menbers were often on the West Coast for formal testing. The remaining staff members were supporting the testing effort by addressing those problems that were written up as emergency or critical problem reports.

During SQT II, the maintenance contractor was still stafiing positions for the group that would be maintaining the system. They were also getting bardware and software installed to "imitate" the PMO system. They were still working on this task during the last month that ORNL was on the project, so many of the emergency situations that occurned as new sites were added to the "live" system were handled by ORNL and the PMO. Because of these situations and time constraints, the maintenance contractor had litte experience with dealing with system problems before they took over maintaining the system. 


\section{LESSONS I.EARNED}

ORNL participated actively in the ICDB formal testiog process, both in writing the TCRs and in on-site assistance. As a means to an end, the process was worth the time and effort expended. However, from the point of view of resource utilization (ORNL personnel spent the better part of a year on the West Coast), ORNL generally felt that there might have been a better way to accomplish the same results. It certainly would have been more convenient for East Coast residents to have conducted more of the tests on the East Coast; however, the testing was performed in connection with the terminal system whose developers were located on the West Coast. The following list represents the "lessons leamed" on both the testing process and the transition period from an ORNL perspective

- The most important lesson keamed is that all testing including all functionality, integration of code developed at different sites, and technical testing, should have been completed successfully prior to ANY formal, controlled testing. Although each site was responsible for testing the code developed by that site, ORNL was responsible for integrating all modules. Much of the ORNL code written for communications and data transfers could not be tested unfil development activities at other sites were complete. Thus, it was impossible to test all of the ORNL code in advance. Additional time should have been provided for integration testing.

- In-process reviews of code and functionality were conducted; however, defticiencies were not always corrected in a timely manner. The easy solutions seemed to be accomplished quickly, but the hard problems continued to plague integration testing for much longer than reasonable.

* Less time spent in repetitive testing of the same fupctions and more time for fixing problems would have beet a more efficient use of time. There was hardly time to fix problems before another test (more travel) was scheduled.

* TCRs were not an effective way to test a system because they listed specific steps and used canned data to produce expected results. Nothing was random, and many functional inaccuracies were noticed only when testers stopped using TCRs and just tried to "break" the system.

* The TCRs might have been mote effective if someone other than the developers had written them and if they bad been prepared earlier. For example, TCRs for some modules were written almost at the last minute because the modules were incomplete or were being revised. 
- There were a lot of TCRs written for the functional requirements, but one whole subsystem (SADBA) was never tested in this manner. It seems to be rather robust; therefore, perhaps the system personnel who used it did a better job of testing than was done through the TCRs.

* End-to-end testing before all components were operational was a mistake. It cost a tremendous loss of resources (tiune and money) to fly the testers and the developers who were supporting the testing to the West Coast for lengthy periods of the, especially when they had to wait for fixes to code that bad never previously been tested.

- For the developer to provide test data and test scenarios was not wike. PMO determined that TCRs required data sets with certain characteristics and specific TCNs and pjanned to develop these data sets. Because ORNL did not have the functional knowledge of MTMC data to make all appropriate changes, ORNL's conversion of cargo shipment records to manifest-type records and vice versa caused a lot of unnecessary confusion for the testers.

* Large data sets $(9,000,000$ database rows) stould have been available for performance testing prior to SQT. Performance testing for the first time during SQT caused the failure of the first SQT.

* New requirements were reassigned from MME to ORNL and to WPS just prior to and duting SDT and the first SQT. This functionality was not ready for informal integration testing prior to formal testing, and a lot of the functionality falled SQT.

- Testing of data that originated at the hubs was difficult because the WPS process for loading data from the bubs into the terminal system was inconsistent and undependable. This particular process continued to cause problems through SDT-II. The ability of WPS to accept data from the hubs should have been available much earlier than it was, with sufficient time to test and retest this process prior to any formal testing-

* The testing process was one method of convinging the end-users of the system that the system was effective. Additional training was also provided.

* Either the maintenance contractor should have been on board much sooner or ORNL should have remained on active status much later. The many small problems which occurred upon implementation would have been much easier for ORNL personnel to Identity and fix than they bave been for the maintenance contractor, who was unfamiliar with the system. 


\section{CONCLUSIONS}

Frequently research and development organizations are immersed in the research, but never reach the end of the development stage. The ORNL team worked from initial requirements gathering, through requirements analysis, and through design activities; they assisted with development tasks, integrated the system components (both software and hardware), participated in testing provided assistance during initial implementation, and provided partial training materials to the maintenance contractors.

The system testing period was a time filled with a great deal of stress brought about by the tight deadlines and the formal testing environment. Some tasks that were assignè to other organizations were completed by ORNL in order to ensure that they were completed. Though having ORNL write the TCRs for testing was unexpected, it provided a valuable experience with this highlystructured testing methodology.

In the real world, both govermment and industry must be cost-conscious. It is imperative to accomplish as moch as possible within as short a time as possible with whatever resources are avaitable. The very formal SOT with structured TCRs that provided documented evidence and were repeatable as often as necessaty provided this environment.

The ORNL team derived substantial satisfaction from the success of ICDB. The projext ended with goals met. 
•

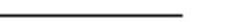




\section{APPENDXX A}

LIST OF FUNCTIONAL TCRS SORTED BY TEST SET 


\section{LIST OF TCRs SORTED BY TEST SETS}

Phase 1: Recoros originating at THE Regional Datamase and Passed to WPS va one fiUB

Note: Sets $1-1$ through $1-9$ test processing of booking and ATCMD records from the Regional to WPS sites

Pass/Fail

Set 1-1: Test booking diata load

R1-113-BKO-1 Data loads of batch loads of booking data (from METS)

R1-113-BKG-2 Data loads of batch loads of booking data (from METS)

R1-113-BKG-3 Data loads of batch loads of booking data (from METS)

Set 1-2: Test matchup of booking and ATCMD data

R1-113-BKG-4 Matches of batch booking and batch ATCMDs (booking loaded first)

R1-113-BKG-5 Data loads of batch loads of booking data with no matches to ATCMDs

Set.1.3: Build ATCMDs on-line at the Regional

RI-121-exp02

R1-121-exp03

R1-121-exp04

R1-121-exp05

R1-121-HAZ

RI-12I-exp06

R1-121-exp07

R1-121-exp08

R1-121-exp10

R1-121-exp11

R1-121-exp12

R1-121-exp13

R1-121-exp14

R1-121-exp14A

RI-121-exp15
Add export van records with single consignee

Add export van HHG records

Add export van POV records

Add export van ammo records

Add export van hazardous records

Add export refrigerated van records

Add export van records with three stopoffis

Add export breakbulk records

Add export HHG breakbulk records

Add export POV breakbulk records

Add export anmo breakbulk reconds

Add export unaccompanied baggage breakbulk records

Add export government vehicle breakbulk records

Add export outsize breakbulk records

Add export mail breakbulk records

\section{Set 1-4:Remaining TCRs to test load of ATCMD data}

R1-113-ATCMD-1

R1-113-ATCMD-2

R1-113-ATCMD-3

R1-113-ATCMD-4

R1-113-ATCMD-5

R1.113-ATCMD-6

R1-113-ATCMD-6A

R1-113-ATCMD-7

R1-113-ATCMD-8

R1-113-ATCMD-9

R1-113-ATCMD-12

R1-113-ATCMD-13

R1-113-ATCMD-14

R1-113-ATCMD-15
Data loads of batch loads of ATCMD data

Data loads of batch loads of ATCMD data

Data loads of batch loads of ATCMD data

Data loads of batch logds of ATCMD data

Data loads of batch loads of ATCMD data

Data loads of batch loads of ATCMD data

Data loads of batch loads of ATCMD data

Data loads of batch loads of ATCMD cata

Data loads of batch loxis of ATCMD data

Data loads of batch loads of ATCMD data

Data loads of batch loads of ATCMD data

Data loads of batch loads of ATCMO data

Data loads of batch loads of ATCMD data

Data loads of batch loads of ATCMD data 
Data loads of batch loads of ATCMD data

R1-113-ATCMD-18

Data loads of batch loads of ATCMD data

R1-113-ATCMO-19

Data loads of batch loads of ATCMD data

R1-117

Data loads of batch loads of ATCMD unit data for Army

Exploding TCNs received via batch load processes

Set 1-5: Building remaining ATCMODs on-line at Regional

R1-121-exp16

R1-121-exp17

R1-121-exp18

R1-121-exp19

R1-121-exp21

R1-122-BKG-VAN1

R1-122-BKG.VAN2

R1-122-refuse
Add export classified breakbulk records

Add export sensitive breakbulk records

Add export controlled breakbulk recordis

Add export hazardous cargo breakbulk records

Add export empty van records

Recall existing container booking data for populating the online buikd screen

Add container booking data to test matchups with batch-loaded booling records

Refustal to allow changes via on-line build to an existing ATCMD record

\section{Set 1-6: Test matchup of booking and ATCMD data}

R1-113-BKG-6

R1-113-BKG-7

R1-113-BKG-8
Matches of batch-loaded booking data and on-line-built ATCMDs

Matches of batch-loaded booking data and on-line-built ATCMDs

Matches of batch-loaded booking data and ATCMDs (ATCMD loaded first)

Set 1.7: Resend/divert ATCMDs

T6-118a1

T6-118a3

T6-118b1

T6-118b2

T6-11862-ext

T6-118b3

T6-118-WPS
Resend ATCMDs by container nbr

Resend and Divert ATCMDs by container no.

Resend ATCMDs by TCN

Divert ATCMDs by container no.

Divert van with CONEX

Resend and Divert ATCMDs by container no.

View Divert to Seattle

Set 18:Correct reiected ATCMD record

G4-112a1

ATCMD error correction and resubmission

Set 1-9: Conect invalid TACs

G4112.33

TAC correction

Set 1-10: Vient corrections on WPS

G4-112-WPS

View corrections to ATCMDs 
Note: Sets I-22 through 1-24 test processing of import mantfest records from the Regional to WPS sites

Pass/Fait

Set 122: Test load of import manifest data

R3-21-import-1 Receipt of import manifest data from OCONUS sources

R3-21-import-2 Receipt of inport manifest data from OCONUS sources

R3-21-import-3 Recejpt of import manifest data from OCONUS sources

R3-21-import-4 Recejpt of import manilest data from OCONUS sources

R3-21-import-5 Receipt of import manifest data from OCONUS sources

R3-21-import-6 Receipt of import manifest data from OCONUS sources

R3-21-import-6A Receipt of import manifest data from OCONUS sources

R3-21-import-7 Receipt of import manifest data from OCONUS sources

R3-21-import-9 Receipt of import manifest data from OCONUS sources

R3-21-import-9A Receipt of import manifest data trom OCONUS sources

R3-21-import-10 Receipt of import manifest data from OCONUS sources

R3-21-import-11 Receipt of import manifest data from OCONUS sources

R3-2I-import-12 Receipt of import manifest data from OCONUS sources

R3-21-import-13 Receipt of import manifest data from OCONUS sources

R3-21-import-14 Receipt of import manifest data from OCONUS sources

R3-21-ingort-15 Receipt of import manifest data from OCONUS sources

R3-21-import-16 Receipt of import manifest data from OCONUS sources

R3-21-import-17 Receipt of import manifest data from OCONUS sources

R3-21-import-18 Receipt of import manifest data from OCONUS sources

Set 1-23: Resend and divert manifests

T2.24a1

$\mathrm{T} 2-24 \mathrm{a} 2$

$\mathrm{T} 2-24 \mathrm{~b} 1$

$\mathrm{T} 2-24 \mathrm{~b} 2$

T2-24c1

$\mathrm{T} 2-24 \mathrm{c} 2$
Resend entire import manifest by VOYDOC to same port

Divert entire import manifest by VOYDOC to a changed port

Resend individual manifested container records by van nbr to same WPS POD

Divert individual manifested container records by van abr to changed WPS POD

Resend individual manifested records by TCN to same WPS POD

Divert individual manifested records by TCN to a changed WPS POD

Set 1-24: Correct rejected manifest record

G4-112+2

Import manifest error correction and resubmission

Note: Sets 1.50 through 1.59 test processing of general requirements

Set 1-50: Test all intransit_visibility regrirenents

G14lal

G1-41a2

Gl-41b1

G1-41c1

G1-41d3
Retrieval of cargo status based on full TCN

Retrieval of cargo status based on partial TCN

Retrieval of cargo records based on container number

Retrieval of cargo records based on SSN

Retrieval based on last uame 


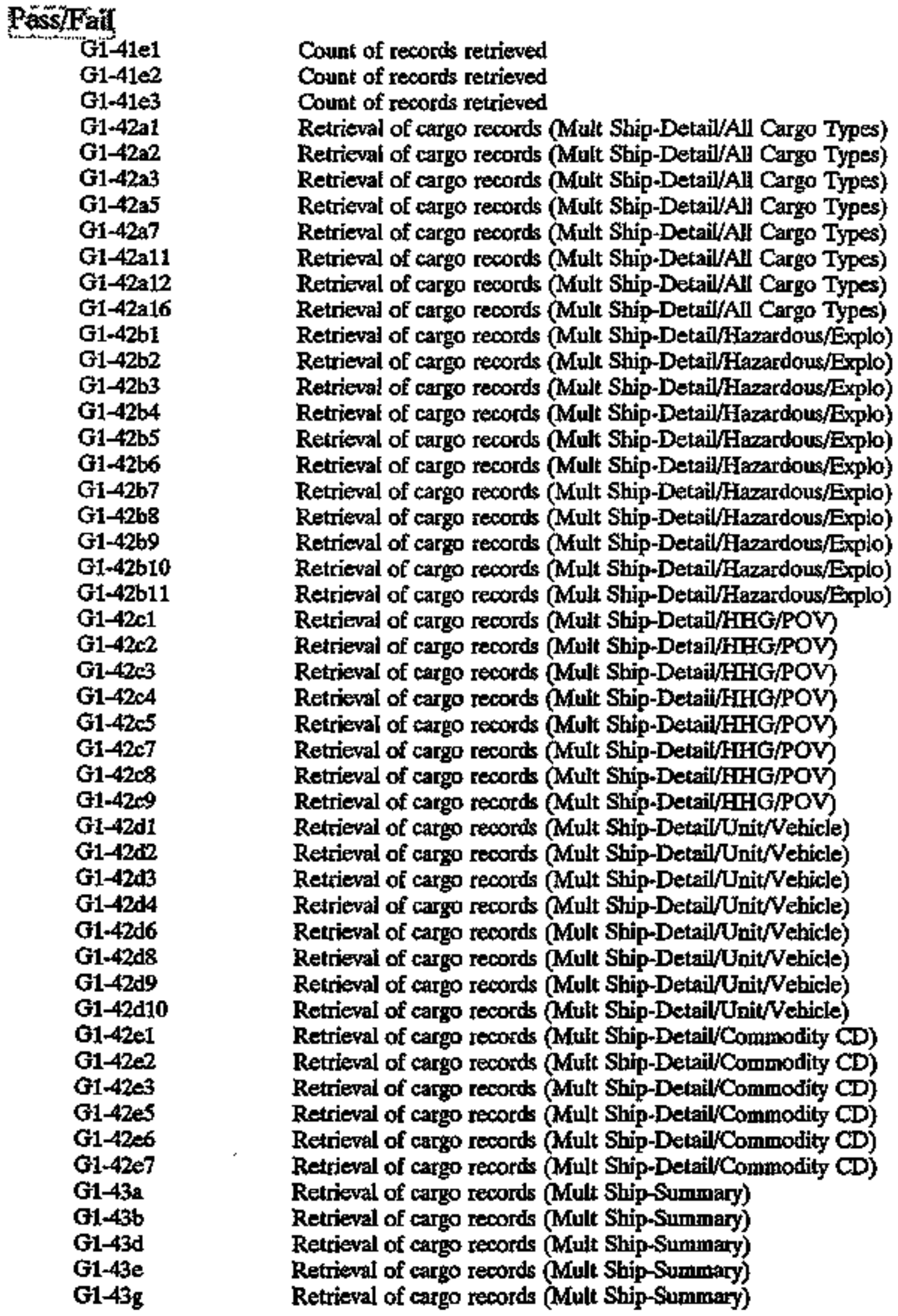




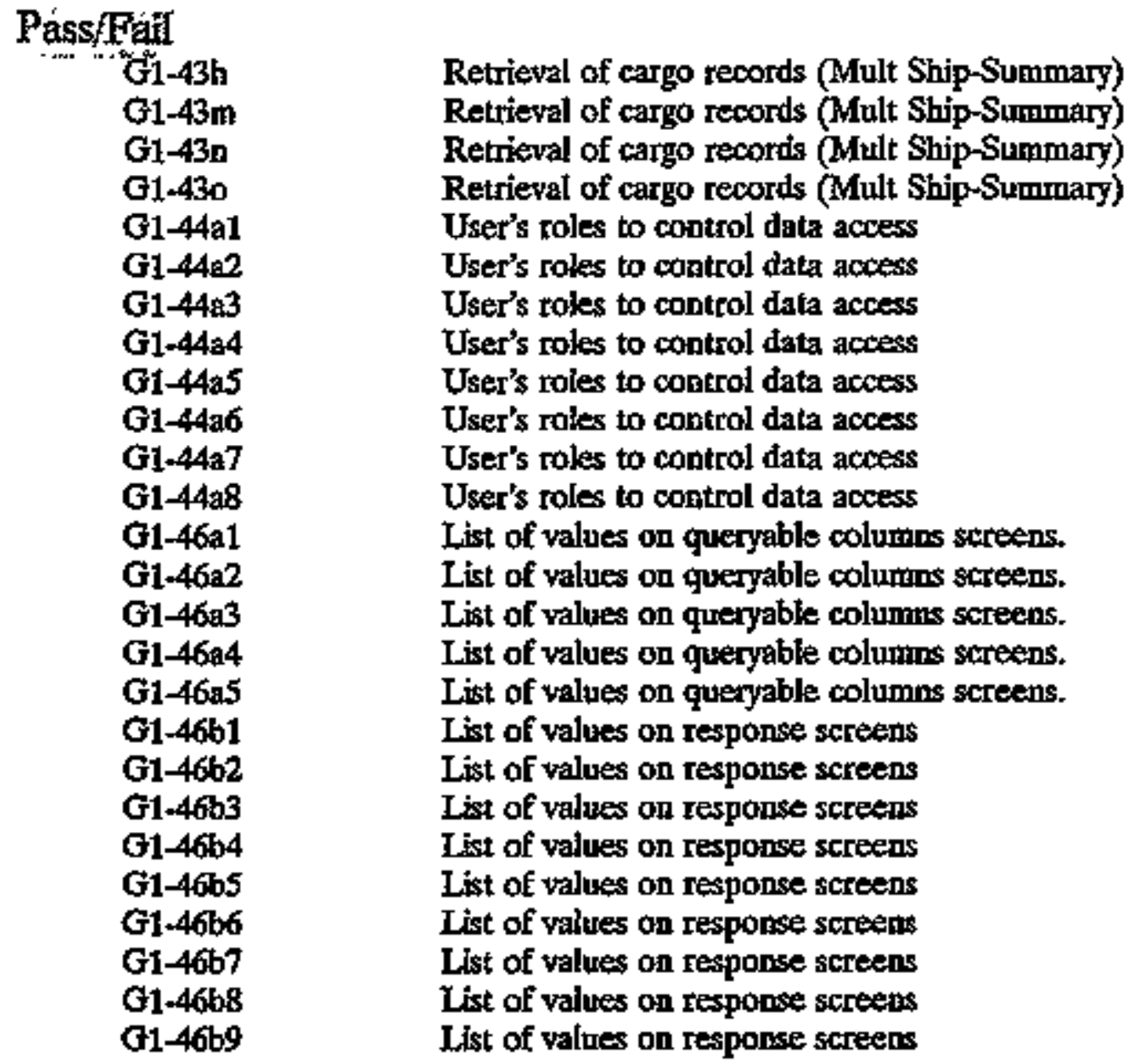

Set 1-51: Resend GTN files; change frequency of transmittal for GTN filles

T3-gta3

Resending data extracts to GTIN

T3-gin4

Change timeframes for seading files to GTN

Set 1.51A: Change frequency of transmittal for GIN files

T3-gto4A Ensure that frequency for sending files to GTN is set to 6 hours

Set 1-52: Resend non-GTN Gles

T1-datax3 Resend capabilities for non-GTN recipients

Set 1-53: Test Reports production

G5 exponhand

G5-exp-hhg/pov-onhand

G5-exp-hazlexp-onhand

G5-imp-onhand

G5-imp-hbg

G5-imp-pov

GS-imp-hag/exp

G5-tcrod-eff

G5-command-ton

GS-mnist-recap
Functionality to produce export onhand shippable cango list

Functionality to produce export hhg/pov onhand shippable cargo list

Functionality to produce export hazardous/explosive shippable targo list Functionality to produce import cargo list

Functionality to produce import hhg cargo list

Functionality to produce import pov cargo list

Functionality to produce import hazardous/explosive shippable cargo list

Functionatity to produce the TCMD Shipper Error Listing

Functionality to produce command tonnage report

Functionality to produce manifest recap M/T by POE report 
Set 1-54: Test code table maintenance to add codes

\begin{tabular}{|c|c|}
\hline $\begin{array}{l}\text { 6-code1 } \\
\text { 6-code2 } \\
\text { 6-comm-add } \\
\text { 6-commg1-add } \\
\text { 6-commg2-add } \\
\text { 6-cdist-add } \\
\text { 6-damage1-add } \\
\text { 6-damage2-add } \\
\text { 6-damage3-add } \\
\text { 6-delreason-add } \\
\text { 6-flag-add } \\
\text { 6-goods-add } \\
\text { 6-hadlng-add } \\
\text { 6-numconv-add } \\
\text { 6-acarr-add } \\
\text { 6-opcode-add } \\
\text { 6-pkg-add } \\
\text { 6-port-add } \\
\text { 6-shipstatus-add } \\
\text { 6-tac-add } \\
\text { 6-typecd-add } \\
\text { 6-typevslcd-add } \\
\text { 6-vanownr-add } \\
\text { 6-vstat-add } \\
\text { 6-cancel-add } \\
\text { 6-delay-add } \\
\text { 6-dodaac-add } \\
\text { 6-gbl-add } \\
\text { 6-ldgterms-add } \\
\text { 6-mode-add } \\
\text { 6-ship-add } \\
\text { 6-add-wPS }\end{array}$ & 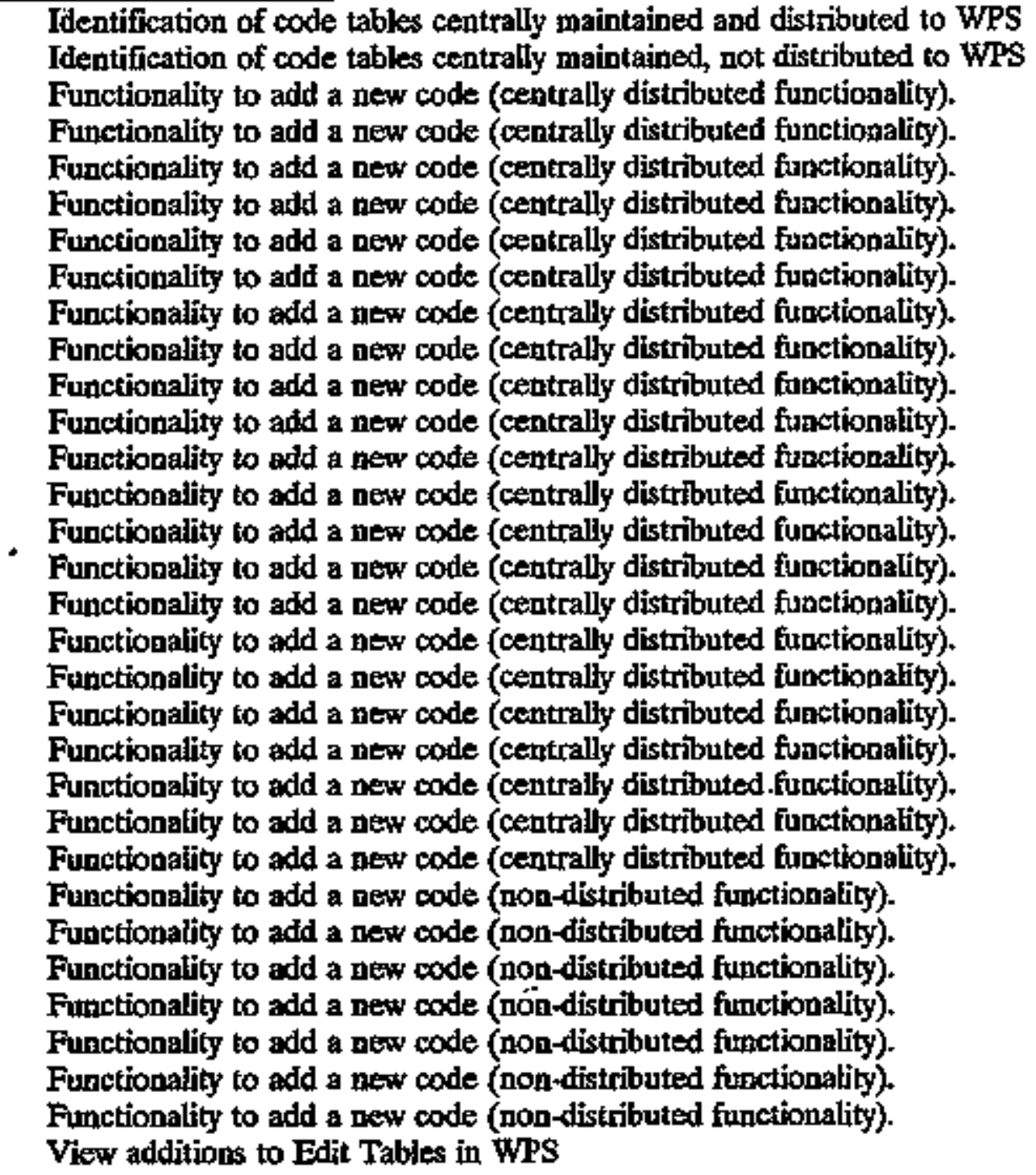 \\
\hline
\end{tabular}

Set 1-55- Test code table maintentance to modify a code

G6-comm-mod Functionality to change a code and/or the description of a code (centrally distributed functionality).

G6-commg1-mod Functionality to change a code and/or the description of a code (centrally distributed functionality).

G6-commg2-mod Functionality to change a code and/or the description of a code (centrally distributed functionality).

G6-cdist-mod Functionality to change a code and/or the description of a code (centrally distributed functionality).

G6-damage1-mod Punctionality to change a code and/or the description of a code (centrally distributed functionality)

G6-daniage2-mod Functionality to change a code and/or the description of a corde (centrally distributed functionality) 
Go-damage3-mod

G6-delreason-mod

G6-flag-mod

G6-goods-mod

G6-tundlng-mod1

G6-numconv-mod

G6-ocart-mod

G6-opcode-mod

G6-pkg-mad

G6-port-mod

G6-shipstatus-mod

G6-tac-mod

G6-typedi-mod

G6-typersicd-mod

G6-vanownr-mod

G6-v8tat-mod

G6-cancel-mod

G6-delay-mod

G6-dodaac-mod

G6-ldgterms-mod

G6-mode-mod

G6-ship-mod

G6-gbl-mod

G6-mod-WPS
Functionality to change a code and/or the description of a code (centrally distributed functionality)

Functionality to change a code and/or the description of a code (centrally distributed functionalify)

Functionality to change a code and/or the description of a code (centrally distributed functionalify)

Functionality to change a code and/or the description of a code (centratly distributed functionality)

Functionality to change a code and/or the description of a code (centrally distributed functionality)

Functionality to change a code and/or the deseription of a code (centrally distributed functionality)

Functionality to change a code and/or the description of a cole (centrally distributed functionatity)

Functionality to change a code and/or the description of a code (centrally distributed functionality)

Functionality to change a code and/or the description of a code (centrally distributed functionality)

Functionality to change a code and/or the description of a code (centrally distributed functionality)

Functionality to change a code and/or the description of a code (centrally distributed functionality)

Functionality to change a code and/or the description of a code (centrally distributed functionality)

Functionality to change a code and/or the description of a code (centrally distributed functionality)

Functionality to change a code and/or the description of a code (centrally distributed functionality)

Functionality to change a code and/or the description of a code (centrally distributed functionality)

Functionality to change a code and/or the description of a code (centrally oistributed functionality)

Functionality to change a code and/or the description of a code (non-distributed functionality).

Functionality to change a code and/or the description of a code (non-distributed functionality)

Functionality to change a code and/or the description of a code (non-distributed functionality)

Frtuctionality to change a code and/or the description of a code (non-distributed functionality)

Functionality to change a code and/or the description of a code (non-distributed functionality)

Functionality to change a code and/or the description of a code (non-distributed functionality)

Functionality to change a code and/or the description of a code (non-distribnted functionality)

View modiffications to Edit Tables in WPS 
Set 1-56: Test code table maintenance to delete a code

G6-conm-del Functionality to delete a code (centrally distributed functionality). G6-commg1-del Functionality to delete a code (centrally distributed functionality).

G6-commg2-del

G6-cdist-del

G6-damagel-del

G6-damage2-del

G6-damage3-del

G6-deireason-del

G6-Aag-del

G6-goods-del

G6-huding-del

G6-numconv-mod2

G6-ocarr-del

G6-opcode-del

G6-pkg-del

G6-port-del

G6-shipstatus-del

G6-tac-del

G6-typed-del

G6-typerslet-del

G6-vanownr-de]

G6-vstat-del

G6-cancel-del

G6-delay-del

G6-dodaac-del

G6-gbl-del

G6-idgterms-del

G6-mode-del

G6r-ship-del

G6-del-WPS
Functionality to delete a code (centrally distributed functionality).

Functionality to delete a code (centrally distributed functionality).

Functionalizy to delete a code (centrally distributed functionality). Functionality to delete a code (centrally distributed functionality). Functionality to delete a code (centrally distributed functionality). Functionality to delete a code (centrally distributed functionality). Functionality to delete a code (centrally distribated functionality). Functionality to delete a code (centrally distributed functionality). Functionality to delete a code (centrally distributed functionality). Functionality to modify a code (centrally distributed functionality). Functionatity to delete a code (centrally distributed functionality). Functionality to delete a code (centrally distributed functionality). Functionality to delete a code (centrally distributed functionality). Functionality to delete a code (centrally distributed functionality). Functionality to delete a code (centrally distributed functionality). Functionality to delete a code (centrally distributed functionality). Functionatity to delete a code (centrally distributed functionality). Functionality to delete a code (centrally distributed functionality). Functionality to delete a code (centrally distributed functioaality). Functionality to delete a code (centrally distributed functionality). Functionality to delete a code (non-distributed functionality). Functionality to delete a code (non-distributed functionality). Functionality to delete a code (non-distributed functionality). Functionality to detete a code (non-distributed functionality). Functionality to delete a code (non-distributed functionality). Functionality to delete a code (non-distributed functionality). Functionality to delete a code (non-distributed functionality). Verify dejetions to Editt Tables in WPS

Sel 1-57: Reviewring outstanding discharge dates; enteringlehecking discharge dates

R6-disch-dts

R6-voy4

R6-voy5

Reviewing vessels with outstanding discharge dates

Dates entered by functional manager

Dates received from OCONUS via TTU data extract

Set 1-58: Checking discharge dates

R6-voys

Dates received from OCONUS via TTU data extract 
Set 1.59: Utilities

G6-util-vaix1 G6-util-unix2A G6-util-upix2B G6-util-unix2C G6-util-iq1 G6-util-iq2A G6-util-iq2B G6-util-tq2C
Printing UNIX files (not IQ) to user's PC Downloading UNIX files (not IQ) to user's PC drive A Downloading UNIX fles (not IQ) to user's PC drive B Dowrbading UNIX files (not IQ) to user's PC drive $C$ Printing IQ files to user's PC

Downloading IQ files to user's $P C$ dive $A$ Downkading IQ files to user's PC drive B Downloading IQ files to user's PC drive C

Set 1-60: Export Manifest distribution

Reg-G-mist-01 Distributing export manifest files

Set 1-61: Export Manifest distribution

Reg-G-mist-002 Printing export manifest at Hub

Set 1-62: Export Manifest distribution

Reg-G-mEst-003 Prepare export manifest distribution tables at Hub

Set_-63:10

RG-IQ-00I Use of IQ for ad hoc queries

Set 1-64:IO

Reg-G-Fort-to-Port Process to add/change/delete unit cargo

Set 1-70: WPS autoload of a dataset with multiple data conditions GTR-01 Datesset to test interfaces, reports, etc.

Set 1-71: WPS tally transactions on selected reconds and vessels

Import tally transaction 01

Import tally transaction 02

Import tally transaction 03

Export tally transaction 01
Discharge records on import manifests

Discharge vessel on import manifests

Disposition records on import manifests

Recejpt records on export cargo

Set 1-72: WWS loading of recoris to test reject provessing
Export TO6-rej
Rejected duplicate records

Set 1-73: WPS manifest call (export manifest) MFST-Call-WPS 


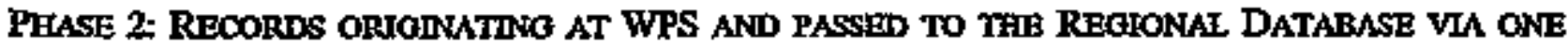
HWB

PassiFaif

Set 2-1: Perform export data loads (R2-Exportoxx on Regional)

Export or Add - Vessel Control Register and export autoload from floppy

Export 02 Add - Van records with single consignee

Export 03 Add - Van HHGS records

Export 04 Add - Van POV recoris

Export 05 Add - Van AMMO records

Export 06 Add - Refrigerated Van records

Export 07 Add - Breakbulk records

Export 08 Add - Breakbulk records

Export 09 Add - Breakbulk records

Export 10 Add - General Cargo Breakbulk records

Export 11 Add - HHGS Breakbulk records

Export 12 Add - POV Breakbulk records

Export 13 Add - AMMO Breakbulk records

Export 14 Add - Unacc Baggage Breakbulk records

Export 15 Add - Govn't Vehicle Breakbulk records

Export 16 Add - Mail Breakbulk records

Export 17 Add - Classifited Breakbulk reconds

Export 18 Add - Sensibive Breakbulk records

Export 19 Add - Controlled Breakbulk records

Export 20 Add - Fazardous Cargo Breakbulk records

Export 21 Add - Unitized/CONEX records

Export 22 Add - Empty Van records

Export 23 Add - Laaded Ro/Ro Van records

Export 23A Assign booking number to breakbulk records and run query

Export B01 Create records to test Tally, Regression, Manifest Call, Manifest Adjustment and History

Set 2-2: Perform import data bads (R3-Import-oxox on Regional)

Import 01 Create - Vessel Control Register

Import 01F Upload of floppy disk to test import tally

Import 01FF Create van with multiple commodities

Imoport T01 Autoload to test Import Tally and Regression

Set 2-3 Perform export status changes (R5-Export-xx on Regional)

Export 24 Correct - Van Records by RECNO

Export 25 Correct - Vau Reconds by TCN

Export 26 Correct - Van HHGS Records by RECNO

Export 27 Correct - HHGS Van Records by TCN

Export 28 Correct - POV Van Records by RECNO

Export 29 Correct - POV Van Records by TCN

Export 30 Correct - AMMO Van Reconds by RECNO

Export 31 Correct - AMMO Van Records by TCN

Export 32 Correct - Refigerated Van Records by RECNO(Add second seal)

Export 33 Correct - Refirgerated Van Records by TCN(Add second seal)

Export 34 Correct - Breakbulk Records by RECNO 
Export 35 Correct - Breakbulk Records by TCN

Export 36 Correct - Breakbulk Records by RECNO

Export 37 Correct - Breakbulk Records by TCN

Export 38 Correct - Breakbulk Records by RECNO

Export 39 Correct - Breakbulk Records by TCN

Export 40 Correct - Breakbulk General Cargo Records by RECNO

Export 41 Correct - Breakbulk general cargo records by TCN

Export 42 Correct - HHGS Breakbulk reconds by RECNO

Export 43 Correct - HHGS Breakbulk Records by TCN

Expott 44 Correct - POV Breakbulk records by RECNO

Export 45 Correct - POV Breakbulk Records by TCN

Export 46

Export 47

Export 48

Export 49

Export 50

Export 51

Export 52

Export 53

Export 54

Export 55

Export 56

Export 57

Export 58

Export 59

Export 60

Export 61

Export 62

Export 63

Export 64

Export 65

Export 66

Export 67

Export 68

Export 69

Export 70

Export 71

Export 72

Export 73

Export 74

Export 75

Export 76

Export 77

Export 78

Export 79

Export 80

Export 81

Export 82

Correct - AMMO Breakbulk records by RECNO

Correct - AMMO Breakbulk Records by TCN

Correct - Unaccompanied Baggage Breakbulk records by RECNO

Conrect - Unaccompanied Baggage Breakbulk Records by TCN

Correct - Government Vehicle Breakbulk Records by RECNO

Correct - Government Vehicle Breakbulk Records by TCN

Correct - Mail Breakbulk Records by RECNO

Correct - Mail Breakbulk records by TCN

Correct - Classified Breakbulk Records by RECNO

Correct - Cjassified Breakbulk Records by TCN

Correct - Sensitive Breakbulk Records by RECNO

Correct - Sensitive Breakbulk Records by TCN

Correct - Controiled Breakbulk Records by RECNO

Correct - Controiled Breakbulk Records by TCN

Correct - Hazandous Cargo Breakbulk Records by RECNO

Correct - Fazardous Cargo Breakbulk Records by TCN

Correct - Unitized/CONEX Recorts by RECNO

Correct - Unitized/CONEX Records by TCN

Correct - Eupty Van Records by RECNO

Correct - Empty Van records by TCN

Cortect - Loaded Ro/Ro Van by RECNO

Correct - Loaded Ro/Ro Van by TCN

Change - TCN by RECNO

Change - TCN by TCN

Delete - Records by TCN

Delete - Records by RECNO

Delete - Records by Container Numbers

Mode to Lift - by RECNO

Mode to Lift - by TCN

Mode to Lift - by Container Number

Change - STOW by TCN

Change - STOW by RECNO

SPLIT/STOW Location - by RECNO

SPLITSTTOW Location - by TCN

SPLITILIFT - by RECNO

SPLIT/LIFT - by TCN

Export 83

MASS CORRECTION - by TCN

MASS CORRECTION - by BVOY 
Set 2-4 Perform export status changes (R5-Export B-xx on Regional)

Export B02 Tally - Source stuff by RECNO

Export B03 Tally - Source stuff by TCN

Export B04 Tally - Source Stuff by container \#

Export BOS Tally - Receipt by RECNO

Export B06 Tally - Receipt by TCN

Export B07 Tally - Receipt by container \#

Export B08 Tally - Receipt by BVOY

Export B09 Tally - Stuff single stop van by RECNO

Export B10 Taly - Stuff single stop van by TCN

Export B11 Tally - Stufi single stop van by container \#

Export B12 Tally - Stuff multi stop van by RECNO

Export B13 Tally - Stuff multi stop van by TCN

Export B14 Tally - Stuff multi stop van by container \#

Export B15 Tally - Split stuff single stop van by RECNO

Export B16 Tally - Split stuff single stop van by TCN

Export B17 Tally - Split stuff single stop van by container \#

Export B18 Tally - Transfer by RECNO

Export B19 Tally - Transfer by TCN

Export B20 Tally - Transfer by container \#

Export B22 Tally - Lift by RECNO

Export B23 Tally - Lift by TCN

Export B24 Tally - Lift by container \#

Export B26 Regress - Lifted to previous status by TCN

Export B27 Regress - Lifted to previous status by RECNO

Export B28 Regress - Lifted to previous status by container \#

Export B30 Regress - Lifted to previous status by VOYDOC

Export B31 Regress - Thl stuffed contents to onhand BB by TCN

Export B32 Regress - Tinl stuffed contents to onhand BB by RECNO

Export B33 Regress - Trml stuffed contents to onhand BB by containet \#

Export B34 Regress - Received to previous status by TCN

Export B35 Regress - Received to previous status by RECNO

Export B36 Regress - Received to previous status by container \#

Export B38 Regress - Deleted to previous status by TCN

Export B39 Regress - Deleted to pretious status by RECNO

Export B40 Regress - Deleted to previous status by container \#

Export B42 Regress - Deleted to previous status by VOYDOC

Export B43 Manifest Export Cargo Reconds

Export B44 Adjust Manifested Export Cargo Reconds/Deletions, Comections and Call Manifest Adjestments By TCN, RECNO or CNTNR

Export B45 Inactivate Export Vessed

Set 2-5 Perform import status changes (R5-Import-ms on Rerional)

Import 13 Correct - by TCN

Import 14 Correct - by VSNR and POSTNO

Import 15 Correct - STOW

Import 16 Correct - TCN 
Import 17 Correct - Breakbulk baggage

Import 18 Correct - Breakbulk Ammo

Import 19 Correct - Breakbulk Mail

Import 20 Correct - Breakbulk HHG

Import 21 Correct - Breakbulk HazMat

Import 22 Correct - Breakbulk POV

Import 23 Correct - Breakbulk Government vehicle

Import 24 Correct - HHO van

Import 25 Correct - Baggage van

Import 26 Correct - Ammo van

Import 27 Correct - Mail van

Import 28 Correct - FazMat van

Import 29 Correct - POV van

Import 30 Correct - Government vehicle van

Import 30a Correct - Empty Van by TCN

Import 31 Stuff - Baggage in a van by TCN

Import 32 Stuff - Ammo in a van by TCN

Import 33 Stuff - Mail in a van by TCN

Import 34 Stuff - HHG in a van by TCN

Import 35

Import 36

Import 37

Import 38

Import 39

Import 40

Import 41

Import 42

Import 43

Import 44

Import 45

Import 46

Import 47

Import 48

Impott 49

Import 50

Import 51

Import 52

Import 53

Import 54

Import 55

Import 56

Import 57

Import 58

Import 59

Import 60

Import 61

Import 62

Import 63

Stuff - HazMat in a van by TCN

Stuff - POV in a van by TCN

Stuff - Govn't vehicle in a van by $T C N$

Correct - Baggage contents by TCN

Correct - Ammo contents by TCN

Correct - Mail contents by TCN

Correct - HHG contents by TCN

Correct - HazMat contents by TCN

Correct - POV by TCN

Correct - Gown't veh contents by TCN

Correct - Van prime w content by TCN

Correct - Van prime w content by POSTNO

Correct - Baggage contents by POSTNO

Correct - Ammo contents by POSTNO

Corrent - Mail contents by POSTNO

Correct - HHG contents by POSTNO

Correct - HazlMat contents by POSTNO

Correct - POV contents by POSINO

Correct - Govn't veh content by POSTNO

Mass Change - By TCN

Delete - Van by TCN

Delete - Brealbalk by TCN

Delete - Van with contents by TCN

Delete - Records by rabge

Delete - Record by container \#

Delete - Recond by POSTNO

Regress - Record by POSTNO

Regress - Record by container \#

Import 64

Regress - Van by TCN

Regress - Breakbulk by TCN 
Import 65 Regress - Van with contents by TCN

Import 66 Regress - By POSTNO range

Import 67 Delete - By mass

Import 68 Regress - By mass

Import 69 Add Van with stop-offs and Contents

Import 70 Mass/Other Changes - By TCN

Import 71 Mass Correction by TCN

Import 72 Mass/Other Changes by VSNR \& POSTNO

Import 75 TCN Change by TCN

Import 76 STOW Change by TCN

Import 77

Import 78

Import 79

Infport 80

Import 81

Import 82

Import 83

Add contents to Unitized/CONEX

Add additional contents Unitized/CONEX

Correct contents Unitized/CONEX by TCN

Correct contents in Unitized/CONEX by VSNR \& POSTNO

Add contents to a Loaded Ro/Ro by TCN

Correct Contents in Loaded Ro/Ro by TCN

Correct Contents in Loaded Ro/Ro by VSNR \& POSTNO

Set 2-6 Perform import status changes (R5-Import-T-xx on Regional)

Import T-02 Review IQ Reports

Import T-03 Tallypischarge - Container \# \& TCN

Import T-03a Transfer \& Regness - Conkainer \# \& TCN

Import T-04 Tally/Discharge - By Single Postno

Import T-04a Transfer and Regress - By Single POSTNO

Import T-05 TallyiDischarge - By Postno Range

Import T-05a Tranfer and Regress - By Postno Range

Import T-06 TallyiDischatge - By Consignee

Import T-06a Transfer by Consignee - Regress by Mass

Import T-07 TallyDischarge - By VSNR

Import T-07a Transfer and Regress - By Mass

Import T-08 TallyDischarge to Mode \& Regress - By Container \# \& TCN

Import T-199 Tally/Discharge to Mode \& Regress - By Single Postno

Import T-10 TallyiDischarge to Mode \& Regress - By Postno Range

Import T-11 Tally/Discharge to Mode by Consiguee Regress by Mass

Import T-12 Tally/Discharge to Mode by VSNR - Regress by Mass

Import T-13 Tally/Discharge - By VSNR

Import T-14 TallyDisposition - By Container \# and TCN

Import T-14a Regress - By Container \# and TCN

Import T-15 Tally/Disposition - By Single Postno

Impart T-15a Regress - By Single Postno

Import T-16 Taily/Disposition - By Postno Range

Import T-16a Regress - By Postro Range

Import T-17 Tally/Disposition - By Consignee

Import T-17a Regress - By Mass

Import T-18 Tally/Disposition - By VSNR

Import T-18a Regress - By Mass

Import T-19 Unstuff Container - by singke post number

Import T-20 Unstuff Container - by TCN

Import T-21 Unstuff Container - by container \# 
Pass

Import T-22 Unstuff Container - by Post number range

Import T-23 Unstuff Contents - by single post number

Import T-24 Unstuff Contents - by TCN

Import T-25 Split Disposition - change TCN and split disposition by single post number

Import ' $T-26$ Unstuff Contents - by post number ranges

Set 2-7 Perform WPS export autoload from diskette (R2-Export 85-Reg)

Export 85 Autoload from Floppy

Set 2-8 Perform Interterminal transier (R2-Exportoxx)

Export 87 Interterminal Transfer - by RECNO

Export 88 Interterminal Transfer - by TCN

Export 89 Interterminal Transfer - by Container Number

Set 2-9 Add POV records (R2-Export-xox on Regional)

Export 91 Add - POV

Export 92 Add - Advance POV

Export 93 Add - POV Van Prime

Set 2-10 Chanke POV records (R.5.Export-xxo on Regional)

Export 94 Change - TCN by RECNO

Export 95 Change - TCN by TCN

Export 96 Change - STOW by RECNO

Export 97 Change - STOW by TCN

Export 98 Delete - by TCN

Export 99 Delete - by RECNO

Export 100 Regress - by TCN

Export 101 Regress - by RECNO

Set 2-11 Automatic Purge (R5-TML_Exp.001 on Regional)

TML-Exp-001

Set 2.12 Flat File Transmittals R1-flatfiles-to-WPS

Ser 2-13 Fiat File Transmittals R1-fios:iles-from-WPS

Set 2-14 Elat Finte Transmittals

R1-atcmds-from-WPS-to-recipients Transmittal of flat fles (ATCMDs) through Hub to ETADs aad NAOMES

Set 2-15. History

History-WPS

Reading from WPS Hrstory

Transmittal of flat files (booling files and contractor pay) from Area Command to WPS terminal

Transmittal of flat files (FMS files) through Hub to FMS

Automatic purge on terminal system 
$$
\text { - - - - }
$$

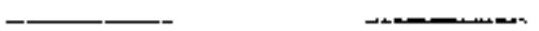




\section{APPENDIX B}

LIST OF TECHNICAL TCRS PREPARED BY ORNL

TO SUPPORT FUNCTIONAL TCR TESTING 


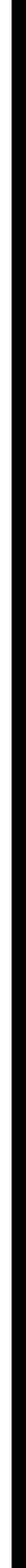




\section{TECHRICAL TCRS}

\section{Prepared for Testing the WPS CONUS Regional Database}

\section{'Technical TCRs to stpport "Receive Data" test requirements}

R1-dataload-BKG1

R1-dataload-BKG2

R1-dataload-ATCMD

R1-dataload-ATCMO-2

R1-dataload-arejrecords

R1-tech-areject

R1-datalogd-unit

RI-dataload-borrect

R1-dataload-shipefí

R2-load-exp01-VSL-REG

R3-dataload-RMPORT-MAN

R3-dataloxd-IMPORT-MAN-2

R3-dataload-LMPORT-MAN-3

R3-dataload-mrejrecords

R3-tech-mreject

R3-load-impio1-VSL-REG

R4-tech-expmandist

R5-dataload-ACI

R6-dataload-VSL-REGIST

R6-dataload-TTU

R6-tech-voy4

R6-tech-ditch-dts
To kat booking data prior to batch-loading ATCMDs

To load booking data after batch-load of ATCMDs

To load ATCMDIASPUR data

To load ATCMD data to check correction of rejected atemd records and invalid TACs

To load recoris that will be rejected during preprocessing

To check for rejected ATCMD/ASPUR records (formerly R1dataload-areject)

To load unit move data with " $A$ " in first position of TCN

To load data to change atcmds (add/delete contents, change LWH, change TAC)

To load data for checking all 39 errors on the TCMD Datly Error Report

To load vessel register data from the WPS xwoydoc table

To load import manifest data

To load import manifest data to check correction of rejected records

To load import manifest data to check correction of rejected records

To load records that will be rejected during preprocessing

To check for rejected import manifest records (formerly R3-dataloadmrejects)

To load dafa from the WPS voydoe table

To check export manifest distribution processes

To load ACI data

To accept the vessel register from METS and send it to WPS

To load TTU data from OCONUS sites

To test fogic for updating discharge dates from screen

To ensure that manifest records exist which outstanding discharge dates

\section{Technical TCRs to support the "Transmit Data" test requirements}

T1-tech-datax1

T1-tech-tatax3

T1-texb-datar6

T2-tech24a

T2-tech24b

T2-tech-portdodaac

T3-tech-gtn1

13-tech-gtn4

T3-tech-gtn3

T6-tech118

T6-tech-rejects
To ensure that data files are generated, transmitted, and moved to a storage directory

To test resend capability for specific data file

To ensure that CDCP data files are generated, transmitted, and moved to a storage directory

To test for resend/divert entire manifest

To check that individual mamifest records were resent or diverted

To check transfer when consignee $=$ dodaac of a port

To ensure that GTN data files are generated, transmitted, and moved to a storage directory

To cbeck changed frequency for GTN

To test resend capability for specific GTN data file(s)

To check that individual atcmid records were resent of diverted

To check records sent from ICDB that are rejected by WPS 
Technical TCRs to stpport "General Requirements" test requirements

G4-tech-112a1

G4-tech-112a2

G4tech-112a3

G6-tech-code1-add

G6-tech-oode1-mod

G6-tech-code1-ted

G6-tech-code2-add

G6-tech-code2-mod

G6-tech-code2-ded

GX-tech-WTL1

GX-tech-WTL2
To check screen corrections of rejected ATCMDs

To check screen corrections of rejected manifests

To check screen corrections of invalid TACs

To check addition of distributed code table data

To check molification of distributed code table data

To check deletion of distributed code table data

To check addition of non-distributed code table data

To check modification of non-distributed code table data

To check deletion of non-distributed pode table data

To check that, when the server is down, the data is saved on the Hub aud then, when the server comes back up, the data automatically goes to the server.

To check that, when a site connection is down, the data is transmitted via SLIP 


\section{APPENDIX C \\ DESCRIPIION OF THE TEST DATA SCHEMA}

This handout was provided to the testers during all tests as Attachment 4 to their test packet. It inchies a list of TCNs sorted by category and the total number of records in each set. The test data schema assisted testers in using the flat-file printout of individual records. TCRs cross-referenced this handout for record counts within each cargo type category. 



\section{Test Data Schema for WPS/WPS CONUS Regional Testing}

The first 6 posilions of the TCN for indivicunt shipmen unit remods will be changed to chable lesters to easity identify the spectic cargo ty|je and the snurbe of dalli, The following is the schema for numbering:

Position

1 = Porl Indicator

2 = Source of datu/Conlginer v. Breakhulk

3-4 = Commodlty Type

$S=$ Comlainer Number or piece count

$0=$ Conient Nutmher

Port 1ndientor (TCN ptsilliton 1)

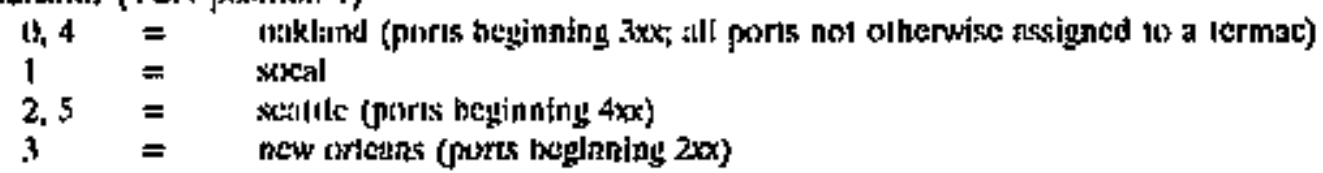

Source of dittat: Containcr vx. Breakbulk and batch vi, online (TCN position 2)

\begin{tabular}{|c|c|}
\hline 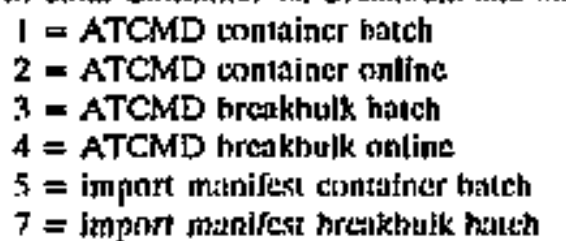 & $=$ \\
\hline
\end{tabular}

Commodity tyje codes (TCN pusilkns 3-4)
10I Ammo/cxplosives if resfer surbi)
14 emply van
D1 Hazardoes
12 wencral teirtso wills sikspoffs:
II POV
03 HHG
13 mail
I4 londed RORO
2) reservej
21 uenur:al cargici
07 Unil targo
15 unacommpanticed biglyinge
22 CONEX-relalied reonrds
(I) Oulsise
16. ethisified
17 sensilive
(i) Ovml vehictex
Is canirolled
23-29 reserved
.M2.31 hanking resords (with matches io hatch ATCMDs)
32-33 monking records (with malches 10 on-line huilds)
wh bokking records (wilh no malches to ATCMDA)

Container nemler, pises count, ar CONEX inditaler whete CONEX is nes in a san (TCN passition 5) (l.s) (contitiner nhr, pioce (tount)

A, B, C \{CONEX indienlor, where CONEX is gol in a van\}

Contents inticalor (TCN position 6)

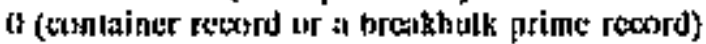

$1-9$ (number of specific tonical reont)

A, B (CONEX wmltined in il van)

Remainder or TCN will be filled with "X"s (except as noted, e.g.. $S$ in pasilion 8 for unjt cargo; sxn in pasitions 6-14 for

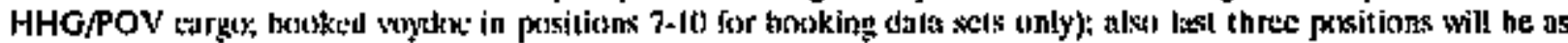
given in the TCN of Ine orięinat dittasce.

Ttsil Dala \$chuma, Juby 7, 1965 
Data Sat - Booking (batch data load);

\begin{tabular}{|c|c|c|c|c|}
\hline Cargo npe category & TCN beg. No. & TCN end. No. & Tot. recorts & Comiments \\
\hline $\begin{array}{l}\text { Booking Set IA } \\
\text { (Container) }\end{array}$ & $013000888 \mathrm{~V}$ & $0130908888 \mathrm{~V}$ & 10 vans & $\begin{array}{l}\text { Match to batch ATCMDs, loaded before } \\
\text { ATCMIDs }\end{array}$ \\
\hline $\begin{array}{l}\text { Bonking Set 2A } \\
\text { (Container) }\end{array}$ & $0131008888 \mathrm{~V}$ & $0131906888 \mathrm{~V}$ & 10 vans & $\begin{array}{l}\text { Match to batch ATCMDs, ioaded after } \\
\text { ATCMDs }\end{array}$ \\
\hline $\begin{array}{l}\text { Booking Set 1C } \\
\text { (Container) }\end{array}$ & $0232008988 \mathrm{~V}$ & $0232902888 \mathrm{~V}$ & 10 vans & $\begin{array}{l}\text { Match to ATCMDs built online, loaded } \\
\text { before ATCMDs }\end{array}$ \\
\hline $\begin{array}{l}\text { Booking Set 2B } \\
\text { (Container) }\end{array}$ & $0233008888 \mathrm{~V}$ & $0233908838 \mathrm{~V}$ & 10 vans & $\begin{array}{l}\text { Match to ATCMDs built online, loaded } \\
\text { after ATCMDs }\end{array}$ \\
\hline Booking Set $1 \mathrm{~B}$ & $0136008898 \mathrm{~V}$ & $0136908888 \mathrm{~V}$ & 10 vans & No matches to any ATCMD records \\
\hline
\end{tabular}

Total of 50 booking reconds losted to database, 40 of which will be matched to ATCMDs 
Datn Set 1 - ATCMD Conbiner (batch data load):

\begin{tabular}{|c|c|c|c|c|}
\hline Cargo type category & TCN beg No. & TCN end. No. & $\begin{array}{l}\text { Act'l reoords } \\
\text { logded" }\end{array}$ & Comments \\
\hline AmmorExplos: Container & 010000 & 010060 & 7 vans & \\
\hline AmmorExplosive: Contents & 010001 & 010061 & t5 contests & \\
\hline Haxardops: Container & 010100 & 010190 & 10 vans & \\
\hline Flazardous: Contents & orolo: & 010199 & 77 contents & $\begin{array}{l}\text { orig. } 57 \text { haz \& } 21 \text { gen; } 1 \\
\text { reject (that t) }\end{array}$ \\
\hline POV: Contziners & 010200 & 010290 & I0 vars & \\
\hline PoV: Contents & $01020(\operatorname{ssn})$ & 01029 (ssi) & 20 contents & Usur 2 per container \\
\hline HHG: Containes & 010300 & 010390 & $10 \mathrm{vans}$ & \\
\hline HHG: Content & 01030 (ssn) & $0: 039(\operatorname{ssn})$ & 28 contents & Max of 9 pes container \\
\hline General: Contafaer Sett 1 & $0 ! 1000$ & 011090 & 10 vans & \\
\hline General; Contents & 011001 & 011099 & 14 contenis & Max of 9 per container \\
\hline Genteral: Reefer Container & 011100 & 011190 & 10 vaps & \\
\hline General: Reefer Contents & 011101 & $0 \pm 1199$ & 40 contents & Max of 9 pet container \\
\hline Loaded RORO & 011400 & 011410 & 2 Ro/Ros & + \\
\hline RO/RO Contents & 011401 & 011411 & 3 contents & \\
\hline Genergl: Empty Container & 031900 & 011990 & 10 emp.vans & Actualyy breakbulk cargo \\
\hline General: Contaìner Set 2 & 012100 & 012180 & 9 vans & \\
\hline General: Contents & 012101 & $0 \$ 2189$ & 63 contents & Orie 64 contents; 1 rejext \\
\hline Van with CONEX & 012200 & 012200 & 1 van & \\
\hline CONEX in van & $07220 \mathrm{~A}$ & $01220 \mathrm{~A}$ & 1 CONEX & $\begin{array}{l}\text { CONEX in vas (TCN e } \\
\text { 012200) }\end{array}$ \\
\hline Content in CONEX in van & 012201 & 012201 & 1 content & $\begin{array}{l}\text { Content in CONEX (TCN = } \\
\text { 01220A) in van }\end{array}$ \\
\hline CONEX not in van & $0122 \mathrm{AO}$ & $0 \pm 22 B 0$ & 2 CONEXs & 2 CONEXs not in a van \\
\hline CONEX contents & 0122AI & 0122B1 & 2 contenis & 2 contents in CONEXs \\
\hline Booking Set $1 \mathrm{~A}$ & $0 \pm 300088 \% 8 \mathrm{~V}$ & $0130908838 \mathrm{~V}$ & 10 vans & Matches to booking teconds \\
\hline Booking Set 2A & $0531008898 \mathrm{~V}$ & $0131908888 \mathrm{~V}$ & 10 vants & Matches to booking reconds \\
\hline
\end{tabular}

-A todal of 365 ATCMD prime records (vans and contents) are actualfy loaded to the database. Two recotds from the original flat files are rejected.

tThis rejected record is corrected during testing. 
Dala Set 2 - ATCMD Container (online bufld):

\begin{tabular}{|c|c|c|c|c|}
\hline Cargo type categry & $\begin{array}{l}\text { TCN beg } \\
\text { No. }\end{array}$ & $\begin{array}{l}\text { TCN end. } \\
\text { Na. }\end{array}$ & Tot records & TCR \& attachnent No. \\
\hline Ammo/Explos: Container & 020000 & & 1 van & R1-121-EXP05 \\
\hline AmmorExplosive: Cuntents & 0200001 & 020003 & 3 contents & RI-121-EXP0S-CL, C2, C3 \\
\hline Hazardous: Container & 020100 & & 1 van & RI-121-HAZ \\
\hline Hazardous: Contents & 020101 & 020105 & 3 contepts & R1-121-HAZ-C1, C2, C3 \\
\hline POV: Containers & 020200 & & 1 van & R1-121-EXP04 \\
\hline POV: Contents & $02020(\operatorname{ssn})$ & 02020 (sso) & 2 contents & R1-121-EXP04-Cl, C2 \\
\hline HFG: Container & 020300 & & 1 van & R1-121-EXP03 \\
\hline HHG: Contents & $02030(s s n)$ & $02030(\mathrm{ssn})$ & 5 contents & R1-121-EXPO3-C1 \\
\hline General: Container & 021000 & & 1 หan & R1-121-EXPO2 \\
\hline General: Conients & 021001 & 021005 & 5 contents & R1-121-EXPO2-C1 \\
\hline Gentecal: Reefer van & 021300 & 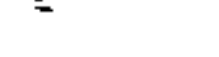 & 1 van & R1-12I-EXPO6 (and trallers) \\
\hline Geoeral: Reeres contenis & 021101 & $02 \pm 102$ & 2 contents & $\mathrm{R} 1-121-\mathrm{EXP} \mathrm{OS} \cdot \mathrm{C} 1, \mathrm{C}$ \\
\hline General: Van with stopotfs & 021200 & & 1 van & R1-121-EXPO7 \\
\hline General: Stp van contents & 021201 & 021202 & 2 contents & R1-121-EXPO7-C1, C2 \\
\hline Baoking Set $1 C$ & $0232008588 \mathrm{~V}$ & $0232908888 V$ & 10 vans & $\begin{array}{l}10 \text { matches to booking; } \\
\text { R1-122-BKG.VAN1 }\end{array}$ \\
\hline Booxing Contents & 023201 \&Ros & $0232918888 \mathrm{~V}$ & 10 contents & $\begin{array}{l}1 \text { content built for each } \\
\text { booked var }\end{array}$ \\
\hline Booking Set 2B & $0233008 \% 8 \mathrm{~V}$ & O23350k888V & 10 vans & $\begin{array}{l}10 \text { malches to booking; } \\
\text { R1-122-BKG-VAN2 }\end{array}$ \\
\hline Booking Contents & 02330tsegsv & $0233918888 \mathrm{~V}$ & 20 contents & $\begin{array}{l}1 \text { content hujla for each } \\
\text { booked val }\end{array}$ \\
\hline
\end{tabular}

-A total of 69 ATCMDs are built online and londed to the databese. 
Data Set 3 - ArCMD Breolsollk (betch dala loai):

\begin{tabular}{|c|c|c|c|c|}
\hline Cargo type caregory & $\begin{array}{l}\text { TCN beg. } \\
\text { No. }\end{array}$ & $\begin{array}{l}\text { TCN end } \\
\text { No. }\end{array}$ & $\begin{array}{l}\text { Act'l tot. } \\
\text { records }\end{array}$ & Comments \\
\hline Ammo/Explosives & 030000 & 030010 & 2 pieces & \\
\hline Hazardous & 030100 & 030190 & 10 pieces & \\
\hline POV & $03020(s+2 n)$ & $03029(\mathrm{ssn})$ & 10 pieces & \\
\hline HHG & 030300 & 030390 & 0 pieces & \\
\hline Unit & $030700 \mathrm{xs}$ & $030790 \times S$ & 10 pieces & \\
\hline Outsize & 030800 & 030830 & 4 pleces & \\
\hline Gowernment Vebicles & 030900 & 030990 & 19 piecess & $\begin{array}{l}10 \text { orig pieces, exploted to } 19 ; \text { see } \\
\text { last } 3 \text { positions of TCN for TCN } \\
\text { beginging } 030900\end{array}$ \\
\hline
\end{tabular}

"A tolal of 55 ATCMDs are foaded to the database.

Date set 4 - ATCMED Breakbolk (online build):

\begin{tabular}{|c|c|c|c|c|}
\hline Cargo rype alegory & $\begin{array}{l}\text { TCN beg. } \\
\text { No. }\end{array}$ & $\begin{array}{l}\text { TCN ead. } \\
\text { No. }=\end{array}$ & $\begin{array}{l}\text { Act'l tot. } \\
\text { records }\end{array}$ & $\begin{array}{l}\text { TCR \& allachments No.; } \\
\text { comments }\end{array}$ \\
\hline Ammo/Explasives & 040000 & 040020 & 3 pieces & R1-121-EXP12 \\
\hline Hazardons & 040100 & 040120 & 3 piexes & R1-121-EXP19 \\
\hline Pov & $04020(\mathrm{ssn})$ & $04022(\mathrm{ssn})$ & 3 pieces & R1-121-EXP11 \\
\hline HHG & 04030 (ssn) & $04032(s s p)$ & 3 pieces & R1-121-EXP10 \\
\hline Outsize & 040800 & 040820 & 3 pieces & R1-121-EXP14A \\
\hline Goverument Vehitlas & 040900 & 0401520 & 3 piectes & R1-121-EXP-14 \\
\hline Genernt BB Cargo & 041000 & $041(12)$ & 3 pieces & R1-121-EXPOB \\
\hline Mail & 041300 & 041320 & 3 pieces & R1-121-EXP1S \\
\hline Unaccomp'd Baggage & $041 \mathrm{SD}(\mathrm{ssn})$ & $04152(s s n)$ & 3 pleces & R1-121-EXP13 \\
\hline Classified & 041600 & 041620 & 3 pleces & R1-121-EXP16 \\
\hline Sensilive & 041700 & 041720 & 3 pieces & R1-121-EXP17 \\
\hline Conlrolled & 04I84in & 041820 & 3 pieces & R1-121-EXP18 \\
\hline Emply Van & 041900 & 041520 & 3 pleces & R1-121-EXP21 \\
\hline
\end{tabular}

"A totil of 42 ATCMDs are built online and loaded to the database- 
Data Set 5 - Inport Manffest Containers (batch data bad)F

\begin{tabular}{|c|c|c|c|c|}
\hline Cargo type category & $\begin{array}{l}\text { TCN beg. } \\
\text { No. }\end{array}$ & $\begin{array}{l}\text { TCN end. } \\
\text { No. }\end{array}$ & $\begin{array}{l}\text { Act'l recordis } \\
\text { losded" }\end{array}$ & Comments \\
\hline AnmosExplor Container & 050000 & 050000 & 7 vans & \\
\hline Antmo/ExplasivenCoutents & 050001 & 050061 & 15 contenns & Max of 9 per container \\
\hline Hazardous: Contriner & 050100 & 050190 & 10 vans & \\
\hline Hazardous: Contents & 050101 & 080199 & 77 contents & orfg $\$ 7$ bez + 21 gen; 1 rejert \\
\hline POV: Cantainers & 050200 & 050290 & 10 vans & \\
\hline POV: Canterts & $0 \cos 0(\operatorname{ssn})$ & $05029(\operatorname{ssa} a)$ & 20 contents & Usu 2 per containes \\
\hline HHG: Container & 050300 & 050390 & 10 vans & \\
\hline FHU: Content & $05030(\sin )$ & 05039 (ssa) & 34 comens & 26 HHG and 8 general \\
\hline General: Container Set 1 & 051000 & 051090 & 10 vans & \\
\hline General: Contents & 051001 & 051099 & 10 contents & Max of 9 per contsiner \\
\hline Geaeral: Reter Container & 051100 & 051190 & 10 vans & 2 of these are reeter RO/ROS \\
\hline General: Reefer Contents & 051101 & 051199 & 28 contents & Max of 9 per container \\
\hline Losded RORO & 051400 & 051410 & 2 RorRos & \\
\hline RORO Contents & 051401 & W1411 & 3 conients & $\cdot$ \\
\hline Generat: Empty Container & 051900 & 051990 & 10 vans & Actually consfdered breakbulk \\
\hline General: Container Set 2 & 052100 & 052180 & 9 vants & \\
\hline General: Contents & 052101 & 052189 & 9 contents & \\
\hline Van with CONEX & 052200 & 052210 & 1 van & \\
\hline CONEX in van & $05220 \mathrm{~A}$ & $05220 \mathrm{~A}$ & 1 CONEX & CONEX in van $(\mathrm{TCN}=0.52200)$ \\
\hline Content in CONEX & 052201 & 052201 & 1 content & $\begin{array}{l}\text { Content in CONEX (TCN = } \\
\text { 05220A) in van }\end{array}$ \\
\hline CONEX not in yan & OS2ZAO & $0522 \mathrm{BO}$ & 2 CONEXS & CONEXs not in van \\
\hline CONEX contents & 0522A1 & 052231 & 2 contents & Contents in CONEX \\
\hline
\end{tabular}

*A total of 281 actual cargo records loaded to the dababase.

fThis rejected record is corrected turing testing. 
Data Set 7 - Import Manifest Breethulk (batch data load):

\begin{tabular}{|c|c|c|c|c|}
\hline Cargo type category & TCAN beg No. & TCN end No. & Act'l tot records & Comments \\
\hline AmmoifErplosives & 070000 & 070010 & 2 piecess & \\
\hline Hazardous & 070100 & 070190 & 10 plects & \\
\hline POV & 07020 (ssn) & $07029(\operatorname{ssn})$ & 10 pieces & \\
\hline HHG & 07030 (ssn) & 07039 (ssn) & 0 pieces & \\
\hline Unic & $070700 \times s$ & $070790 \mathrm{xs}$ & 10 piecess & \\
\hline Outsize & 070800 & 070830 & 4 pienes & \\
\hline Government Vehictes & 070900 & 070990 & 10 pieces & \\
\hline
\end{tabular}

A total of $\mathbf{4 6}$ actual cargo records are loaded to the database. 


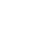




\section{APPEINDIX D \\ A UIST OF HANDOUTS OF \\ FLAT FILE LAYOUTS OF DATA LOADED VIA BATCH INPUT}

This handont was provided to the tester during all tests. It provided a list to the testers of all of the flat-file printouts they were receiving. Attachments $7 \mathrm{~A}-\mathrm{TE}$ were printouts of individual records that matched the criteria described in Appendix $\mathrm{C}$ of this document

Attachment 7A: ATCMD Containers and Breakbulk -PRIME DATA ONLY. These are the dath sets defined in Attachment 4 as Data Sets 1 (container batch input) and 3 (breakbulk batch input)

Attachment 7B: ATCMD Containess and Breakbulk -- PRIMES AND TRAII.ERS. These are the data sets defined in Attachment 4 as Data Sets 1 (container batch input) and 3 (brealbulk batch input)

Attachment 7C-1: BOOKING DATA. These are the data sets defined in Attachment 4 as Booling Sets $1 \mathrm{~A}, 1 \mathrm{~B}$, and $1 \mathrm{C}$

Attachment 7C.2: BOOKING DATA. These are the data sets defined in Attachment 4 as Booking Sets $2 A$ and $2 B$

Altactiment 7D: Import Manifest Containers and Breakbulk -PRIME DATA ONLY. These are the data sets defined in Attachment 4 as Data Sets 5 and 7

Attachment 7E: Import Mantfest Containers and Breakbulk - PRDMES AND TRADLRS. These are the data sets defined in Attachment 4 as Data Sets 5 and 7

Attachment 7F: ACI Data

Attachment 7G: Vessel Register Data

Atlachment 7H: Discharge and Disposition Data (TTU Records) from OCONUS

Attachment 7: Unit Move Records for Army, with an "A" in the first pasition of the TCN (10 records)

Attachment 7J: ATClMD batch changes/corrections (add/Aelete content, change LWH, change TAC) to previously submitted records

Attachment 7K: Data for testing the TCMD Effectiveness Report

Attachment 7L: Duplieate Records, testing reject processing 



\section{APPENDIX E}

\section{TEST ORDER}

This bandout was provided to the test leaders to assist in maintaining control over the order of the testing. 
<smiles>[CH]C</smiles> 


\section{TEST ORDER FOR TCRS (WPS Regional Database)}

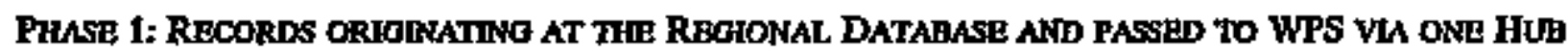
Nole: these tasks may be run concurrently with Phase 2 tasks

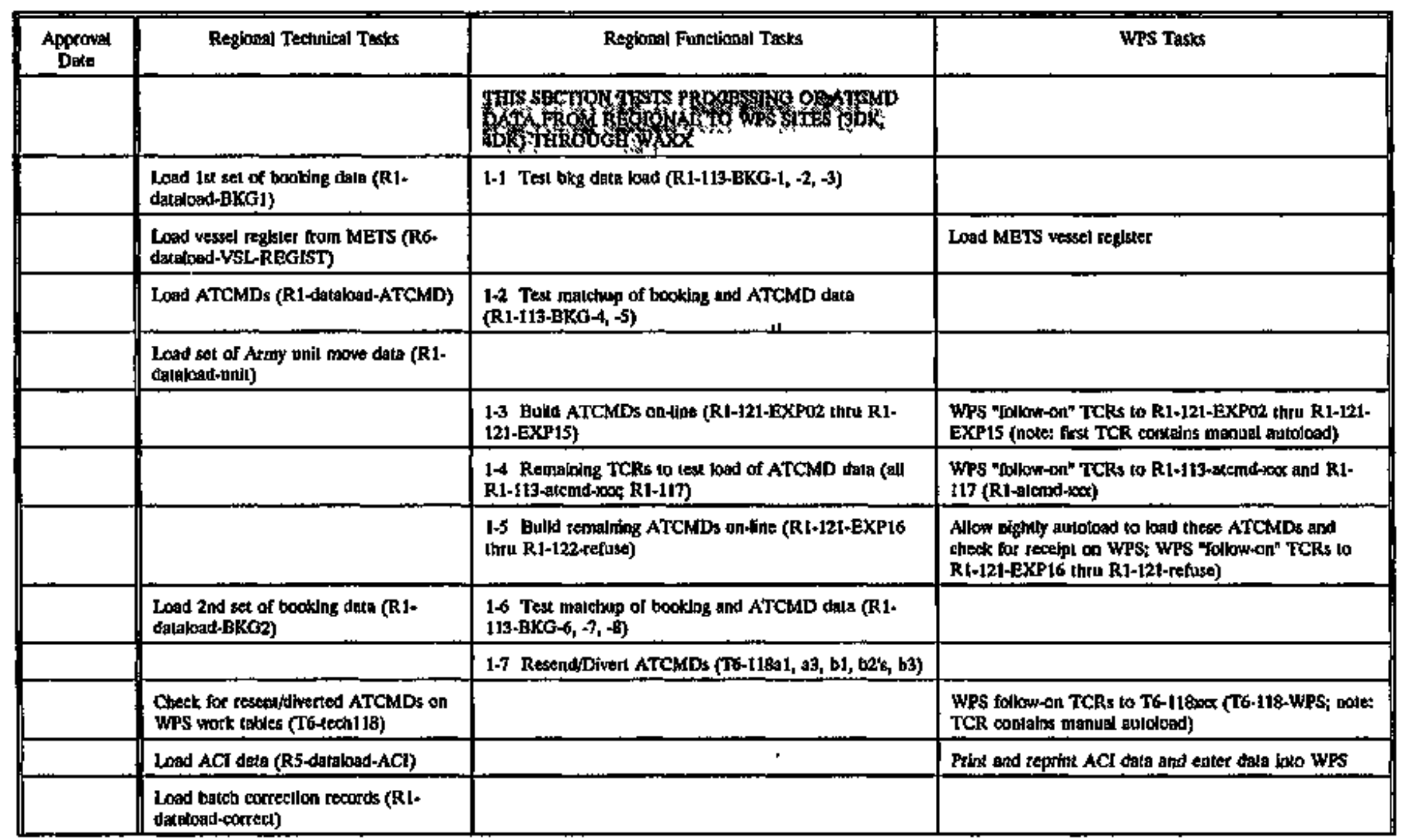




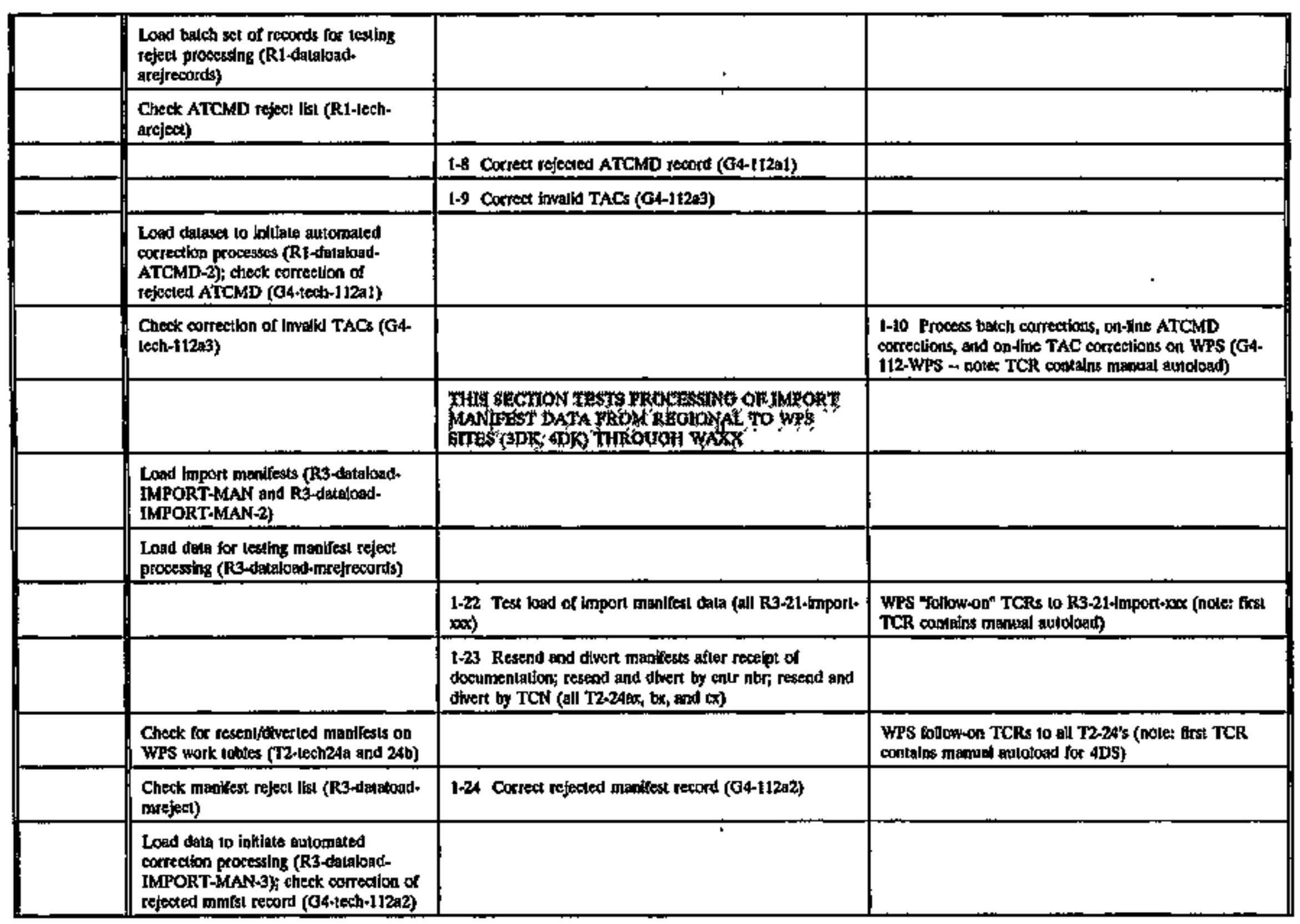




\begin{tabular}{|c|c|c|c|}
\hline & & 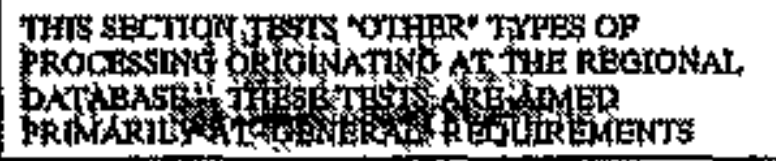 & \\
\hline & & & $\begin{array}{l}1.70 \text { WPS autoked of data sels with multiple data } \\
\text { conditions (GFR-01) }\end{array}$ \\
\hline & & & $\begin{array}{l}\text { 1.7t WTS performs tally transaction on setected } \\
\text { records and vessels (Import tettly transartians-01 - } 03 \text { and } \\
\text { Export IEaly transections-01) }\end{array}$ \\
\hline & $\begin{array}{l}\text { Check dista exiracis for GTN } \\
\text { (T3+ech-gin1) }\end{array}$ & & \\
\hline & $\begin{array}{l}\text { Chect non-GTN dala extracts } \\
\text { (T1-tech-dalaxi, 6) }\end{array}$ & & \\
\hline & & $\begin{array}{l}\text { 1-51 Resend GTN files; ctange frequency o iransmittal } \\
\text { for OTN fites (TH-gtn3, 4) }\end{array}$ & \\
\hline & & $\begin{array}{l}\text { 1-51A Ensure that GnN frequenty is set to } 6 \text { botus alter } \\
\text { lesting is complete (T3-Binte) }\end{array}$ & \\
\hline & $\begin{array}{l}\text { Lond dataset far testing ATCMD } \\
\text { ahlpper effeclivensess conditions (RI- } \\
\text { datitoad-sipefif) }\end{array}$ & $\cdot$ & \\
\hline & & 1-53 Tesl reports produsilon (O5-ex) & \\
\hline & & 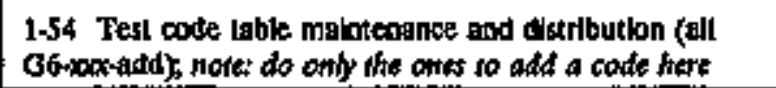 & \\
\hline & 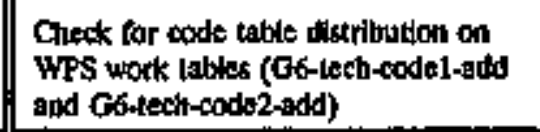 & . & WPS "follow-an" TCR (G6-add-WPS) \\
\hline
\end{tabular}




\begin{tabular}{|c|c|c|}
\hline 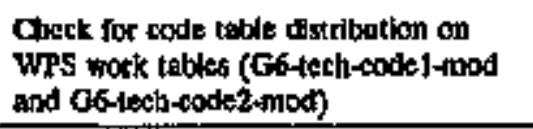 & + & WPS "Folkw-on" TCR (G6-mad-WPS) \\
\hline & 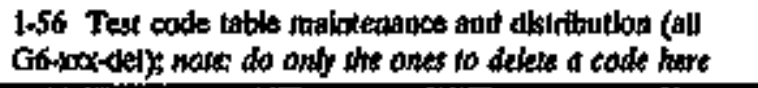 & \\
\hline 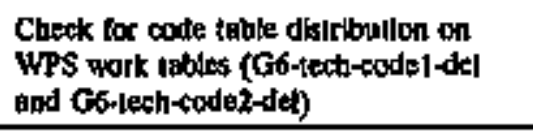 & & WPS "Follow-on" TCR (G6-del) \\
\hline 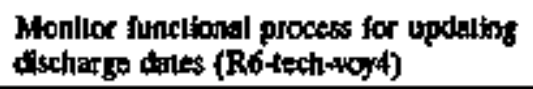 & 1-57a Enlering/chedving dlscharge dates (R6-voy4) & \\
\hline $\begin{array}{l}\text { Load of disctiange dates vita TTU (R6- } \\
\text { dataload-TTU) }\end{array}$ & 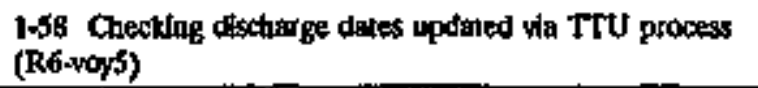 & \\
\hline $\begin{array}{l}\text { Chorkt rexards that were rejected by } \\
\text { WPS (T6-lectorejects) }\end{array}$ & If & $\begin{array}{l}\text { 1-72 WPS TCR for tesling toject procesting (Euport- } \\
\text { TU6.Rej) }\end{array}$ \\
\hline & 160 Export Maniliest dst. processes (Reg-G-nistst-001) & \\
\hline $\begin{array}{l}\text { Oheek export manifest distributlan } \\
\text { processes (R4-tech-expmandisi) }\end{array}$ & 1-61 Export Menifest prims process (Rtg-G-misl-002) & \\
\hline & 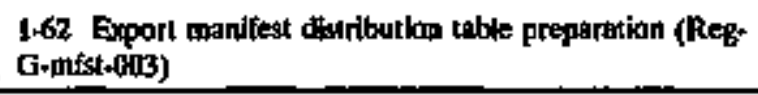 & \\
\hline & $1-63$ 10 (RG-10-001) & \\
\hline $\begin{array}{l}\text { 1-64 Fott-to-poxt processing (Reg-0. } \\
\text { Fort-10.Porl) }\end{array}$ & Check on Regional & Check on WPS \\
\hline
\end{tabular}




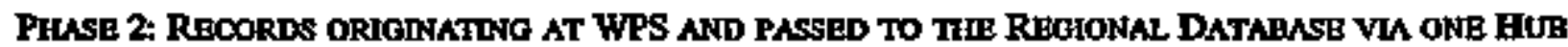
Note: these tasks may be run concuntentip with Phase 1 tasks

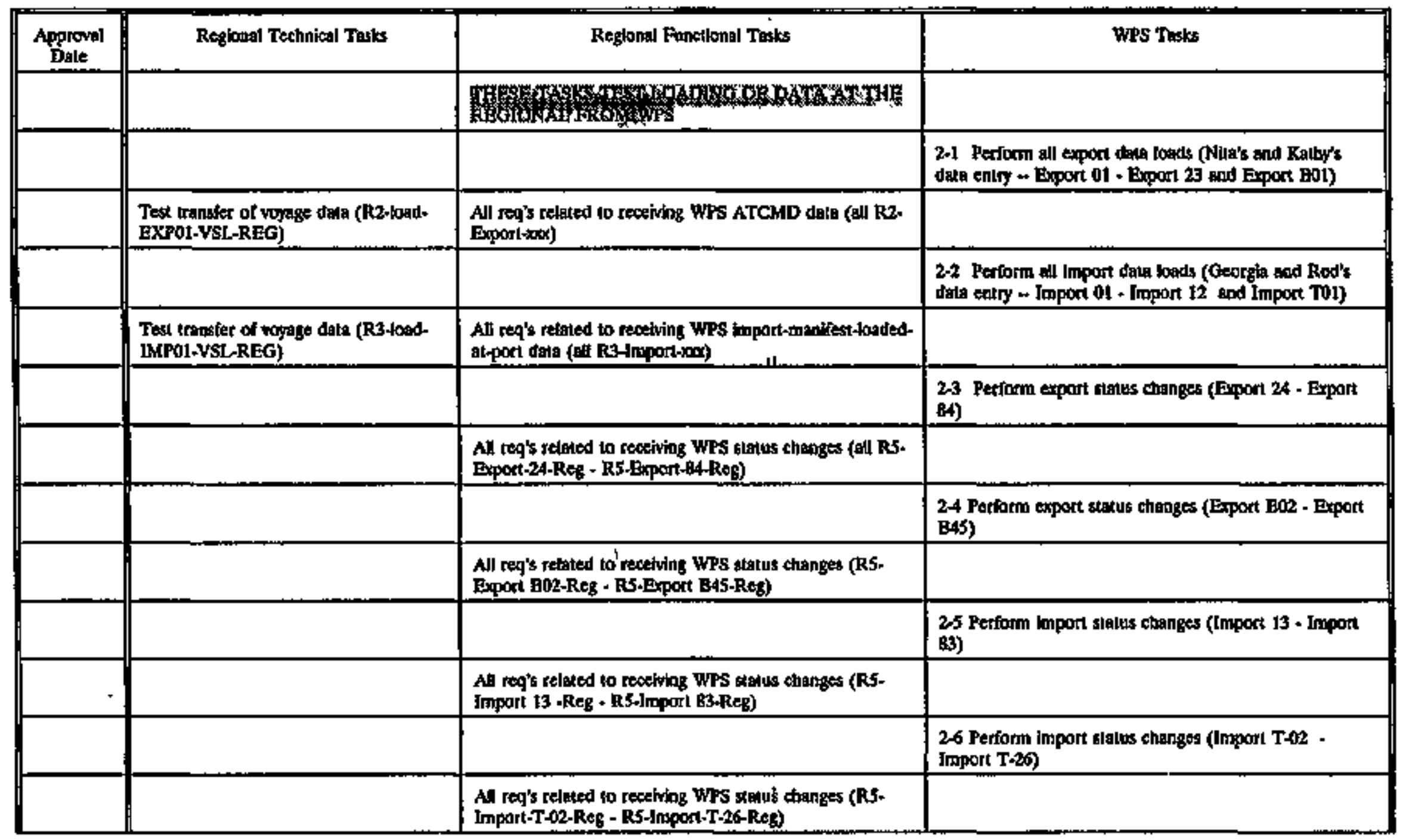




\begin{tabular}{|c|c|c|c|}
\hline & & & $\begin{array}{l}\text { 27.7 Perlorm WPS axport autoload from diskette (Expox) } \\
\text { 85) }\end{array}$ \\
\hline & & $\begin{array}{l}\text { All req's retaled to recotving WPS dete (R2-Export 85- } \\
\text { Reg) }\end{array}$ & \\
\hline & & & $\begin{array}{l}\text { 2-8 Perform Intertemlnal transter (Export } 87 \text { - Eyport } \\
\text { 89) }\end{array}$ \\
\hline & & $\begin{array}{l}\text { Recetring inlortatm'as transtor (R2-Export-87-Rog - R2. } \\
\text { Exporl Bg-Res) }\end{array}$ & \\
\hline & & & 2-9 Add FOV records (Expon 91 - Eppor 93) \\
\hline & & $\begin{array}{l}\text { Recelve new POV records (R2-Export 91-Reg - R2 } \\
\text { Exponl-93-Reg) }\end{array}$ & \\
\hline & & & 2.10 Chenge POV records (Export 94 - Export 101) \\
\hline & & $\begin{array}{l}\text { Recetve changes to POV records (RS-Export 94-Reg - RS } \\
\text {-Expoth-101-Rog) }\end{array}$ & \\
\hline & & 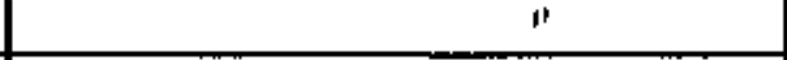 & 2-11 Avlomatic purge (TML-EXP-001) \\
\hline & & Follom-on TCRs to watometic purge (TML-Exp-101-Reg) & 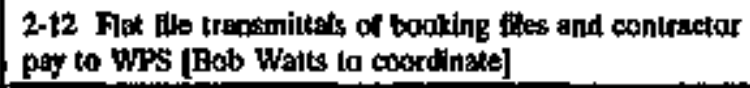 \\
\hline & & & $\begin{array}{l}\text { 2-13 Fat file transmilteis of PMS files from WTS thru } \\
\text { Hub [Bob Watls to coortinate] }\end{array}$ \\
\hline & & & $\begin{array}{l}\text { 2-14 Fot fite Irantmintaks of ATCMDs to ETADs and } \\
\text { NAOMIS [Bob Watts to coordinale] }\end{array}$ \\
\hline & & & 2.15 Acoessing tecords to WFS Hitstory \\
\hline
\end{tabular}




\section{APPENDDX F}

FORMS THAT WERE USED DURING MAISRC TFSTING OF ICDB

Figure F1 DA Form 5005-R. Engineering Change Propasal -- Software. This form was used for writing up problems that were identified during testing. Whoever identified the problem described it in sufficient detail that the developers could then assign priority, responsibility, and a recommended solution.

Figure F2 SQT - WPS Regional Code Upload Log. This form was used to keep track of the status of code uploads to correct problem reports. It was constantly updated, sometimes multiple times a day. This form was developed and maintained by ORNL. 

T.t.

2 Fints

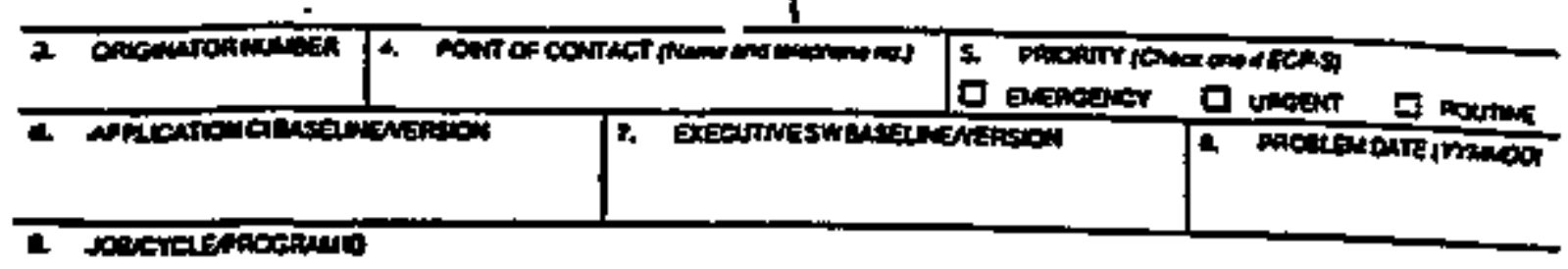

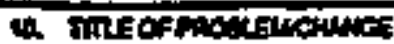

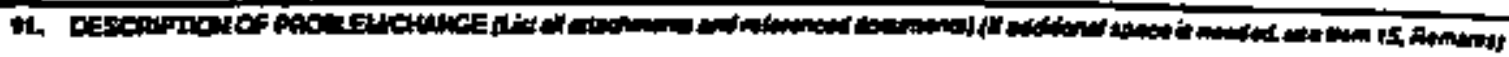

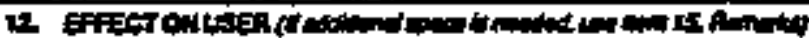

$\geq$

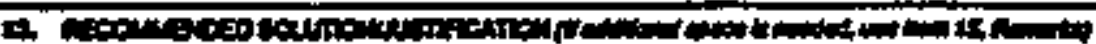

\begin{tabular}{|c|c|c|}
\hline 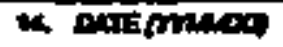 & 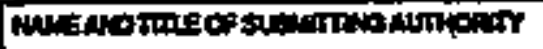 & 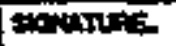 \\
\hline
\end{tabular}




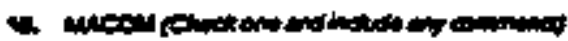

C namate

a mermone

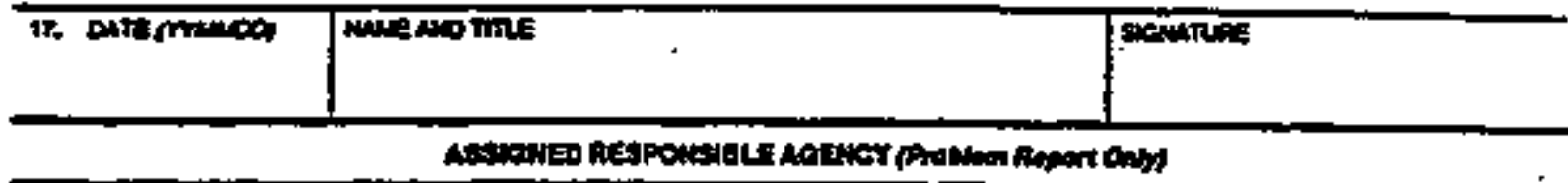

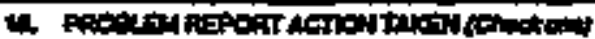

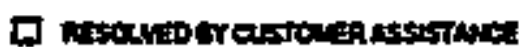

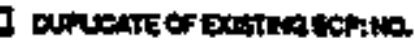

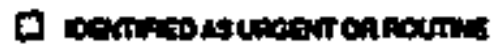

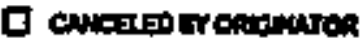

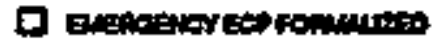

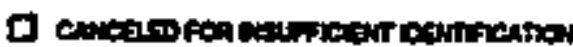

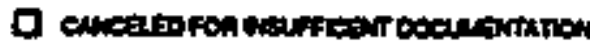

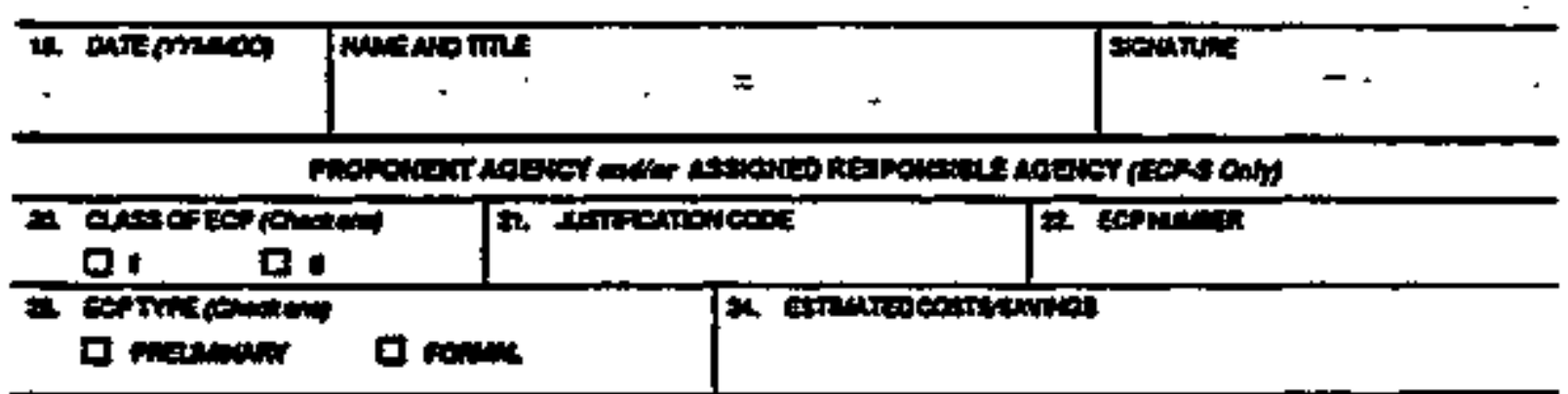

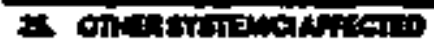

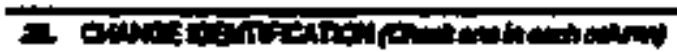

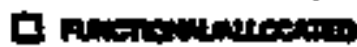

D wat

E utributec

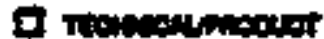

ด in:

O intatestes

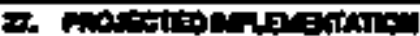

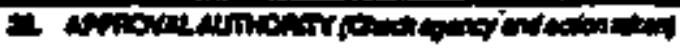

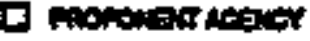

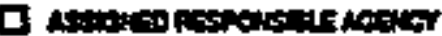

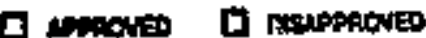

\begin{tabular}{|c|c|c|}
\hline 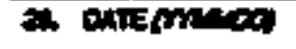 & Hangasome & 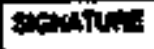 \\
\hline
\end{tabular}




\section{SQT - WPS Regional Code Upload Log}

\begin{tabular}{|c|c|c|c|c|c|c|}
\hline $\begin{array}{c}\text { Date/Time } \\
\text { Changed }\end{array}$ & Code & Functionality & $\begin{array}{c}\text { PR } \\
\text { Nbr }\end{array}$ & Priority & Notes & $\begin{array}{c}\text { Regression Test } \\
\text { Set }\end{array}$ \\
\hline & & & 001 & & & \\
\hline & & & 002 & & & \\
\hline & & & 003 & & & \\
\hline & & & 004 & & & \\
\hline & & & 005 & & & \\
\hline & & & 006 & & & \\
\hline & & & 007 & & & \\
\hline & & & 000 & & & \\
\hline & & & 009 & & & \\
\hline
\end{tabular}




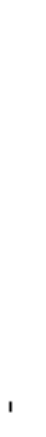


ORNL/TM-13155

\section{INTERNAL DISTRIBUTION}

$\begin{array}{ll}\text { 1. } & \text { M. S. Bronzini } \\ \text { 2. } & \text { G. E. Courville } \\ \text { 3. } & \text { S. G. Hildebrand } \\ \text { 4. } & \text { S. Moore } \\ \text { 5. } & \text { C. I. Moser } \\ \text { 6.8. } & \text { J. P. Rollow } \\ 9 . & \text { R. B. Shelton } \\ \text { 10. } & \text { P.C. Shipe }\end{array}$
11. B. E. Tonn
12-14. L. F. Truett
15. Central Research Lilorary
16. Document Reference Section
17-18. Laboratory Records
19. Laboratory Records - RC
20. ORNL Patent Office

\section{EXTERNAL DISTRIBUTION}

21. Ms. Betty Childers, ICDB Product Management Office, Military Traffic Managemeat Command, 5611 Columbia Pike, Falls Church, VA 22041-5050.

22. Mr. Herb Kaskoff WPS Project Management Ofice, Military Traffic Management Command, 5611 Colurabia Pike, Falls Church, VA 22041-5050.

23. Dr. Thomas E. Drabek, Professor, Department of Sociology, University of Denver, Denver, CO 80208-0209.

24. Mr. Jack Hetman, ICDB Product Management Ofifice, Military Traffic Management Connenand, 5611 Columbia Pike, Falls Church, VA 22041-5050.

25. Mr. Calvin D. MacCracken, President, Calmac Mamufacturing Corporation, 101 West Sheffield Avenue, Euglewood, New Jersey 07631.

26. Ms. Ruth Olgivie, ICDB Produt Mamagement Ofive, Military Traffic Management Command, 5611 Columbia Pike, Falls Church, VA 22041-5050.

27. Mr. George F. Sowers, Senim Vice President, Law Companies Group, Inc., 114 Townpark Drive, Snite 250, Kennesaw, GA 30144-5599.

28. Dr. C. Michael Walton, Paul D. and Betty Robertson Meed Centenniat, Professor and Chairman, Departments of Civil Engineering, College of Engimering, The University of Texas at Austin, Cockrell Hail, Suite 4.2, Austin, TX 78712.

29. ORNL Site Manager, U.S. Department of Energy, Oak Ridge National Laboratory, P.O. Box 2008, Oak Ridge, Temnessee 37831-6269.

30-31. Office of Scientific and Technical Information, U.S. Department of Energy, P.O. Box 62, Oak Ridge, Tennesses 37831 . 